\title{
Involvement of Bcl-2 family members, phosphatidylinositol 3 '-kinase/AKT and mitochondrial p53 in curcumin (diferulolylmethane)-induced apoptosis in prostate cancer
}

\author{
SHARMILA SHANKAR and RAKESH K. SRIVASTAVA \\ Department of Biochemistry, University of Texas Health Center at Tyler, Tyler, TX 75703, USA
}

Received November 6, 2006; Accepted December 21, 2006

\begin{abstract}
Curcumin (diferulolylmethane), an active ingredient derived from the rhizome of the plant Curcuma longa, has anticancer activity in vitro and in vivo. Although curcumin possesses chemopreventive properties against several types of cancer, the molecular mechanisms by which it inhibits cell growth and induces apoptosis are not clearly understood. Our data revealed that curcumin inhibited growth and induced apoptosis in androgen-dependent and -independent prostate cancer cells, but had no effect on normal human prostate epithelial cells. Curcumin downregulated the expression of $\mathrm{Bcl}-2$, and $\mathrm{Bcl}-\mathrm{X}_{\mathrm{L}}$ and upregulated the expression of $\mathrm{p} 53$, Bax, Bak, PUMA, Noxa, and Bim. Curcumin upregulated the expression of p53 as well as its phosphorylation at serine 15 , and acetylation in a concentration-dependent manner. Acetylation of histone $\mathrm{H} 3$ and $\mathrm{H} 4$ was increased in cells treated with curcumin, suggesting histone modification may regulate gene expression. Treatment of LNCaP cells with curcumin resulted in translocation of Bax and p53 to mitochondria, production of reactive oxygen species, drop in mitochondrial membrane potential, release of mitochondrial proteins (cytochrome c, Smac/DIABLO and Omi/HtrA2), activation of caspase- 3 and induction of apoptosis. Furthermore, curcumin inhibited expression of phosphatidylinositol-3 kinase (PI3K) p110 and p85 subunits, and phosphorylation of Ser 473 AKT/PKB. Downregulation of AKT by inhibitors of PI3K (Wortmannin and LY294002) and AKT, or by dominant negative AKT increased curcumininduced apoptosis, whereas transfection of constitutively active AKT attenuated this effect. Similarly, wild-type phosphatase and tensin homolog deleted from chromosome 10 (PTEN) enhanced curcumin-induced apoptosis and, in contrast, inactive PTEN (G129E and G129R) inhibited curcumin-induced apoptosis. Overexpression of constitutively
\end{abstract}

Correspondence to: Dr Rakesh Srivastava, Department of Biochemistry, The University of Texas Health Center at Tyler, 11937 US Highway 271, Tyler, TX 75708-3154, USA

E-mail: rakesh.srivastava@uthct.edu

Key words: Bcl-2, PI3K, AKT, apoptosis, prostate cancer, mitochondria, caspase active AKT inhibited curcumin-induced p53 translocation to mitochondria, and Smac release to cytoplasm, whereas inhibition of AKT by dominant negative AKT enhanced curcumin-induced p53 translocation to mitochondria and Smac release. Our study establishes a role for AKT in modulating the direct action of p53 on the caspasedependent mitochondrial death pathway and suggests that these important biological molecules interact at the level of the mitochondria to influence curcumin sensitivity. These properties of curcumin strongly suggest that it could be used as a cancer chemopreventive agent.

\section{Introduction}

Prostate cancer is the cancer of second largest incidence among the male populations in the USA, and the incidence has increased rapidly in the recent years (1). Prostate cancer cells are only modestly responsive or even unresponsive to the cytotoxic effects of chemotherapeutic agents or radiotherapy. Increased concentrations of cytotoxic drugs and higher dosages of irradiation fail to improve the response to therapy and it leads to resistance to apoptosis in prostate cancer cells. Thus, it is imperative to identify anticancer agents that are non-toxic and highly effective in inducing apoptosis preferentially in tumor cells. Epidemiological data support the concept that naturally occurring compounds in the human diet may be devoid of toxicity and have long lasting beneficial effects on human health. Curcumin [1,7-bis (4-hydroxy-3-methoxyphenyl)-1,6-hepatadiene-3,5-dione; diferulolylmethane], a major constituent of the yellow spice turmeric derived from the rhizomes of Curcuma spp., is one such compound. Curcumin has been reported to have several pharmacological effects including antitumor, anti-inflammatory and antioxidant properties (2-5). It is inhibitory to a broad range of tumors including colon, breast, skin, stomach, duodenum, and soft palate in rodents after oral administration. However, the molecular mechanisms by which it inhibits growth and induces apoptosis in cancer cells are not well understood.

Phosphatidylinositol-3 kinase (PI3K) is a heterodimeric enzyme composed of one $110-\mathrm{kDa}$ catalytic subunit and another $85-\mathrm{kDa}$ regulatory subunit and serves as a major signaling component downstream of growth factor receptor tyrosine kinases $(6,7)$. PI3K catalyzes the production of the lipid secondary messenger phosphatidylinositol-3,4,5-triphos- 
phate, which in turn activates a wide range of downstream targets, including the serine/threonine kinase AKT (6). Full activation of AKT/PKB is PI3K dependent and requires both recruitment to the plasma membrane and phosphorylation on two key residues, $\mathrm{Thr}^{308}$ and $\mathrm{Ser}^{73}(7,8)$. The PI3K/AKT pathway regulates multiple cellular processes, including cell proliferation, differentiation, survival, growth, motility and angiogenesis. We and others have shown that the activated $\mathrm{PI} 3 \mathrm{~K} / \mathrm{AKT}$ pathway provides major survival signals to prostate and many other cancer cells (9-12). Constitutive activation of AKT is frequently described in many types of human cancers (13).

Furthermore, the ectopic expression of AKT induces cell survival and malignant transformation, whereas the inhibition of AKT activity stimulates apoptosis in a range of mammalian cells $(10,12,14-17)$. Recent studies have identified the substrates of AKT that are involved in the pro-cell survival effects, which thus far include glycogen synthase kinase-3, mTOR, FKHR, MDM2, p21, HIF-1, IKK, Bad, and caspase-9 (13,18-20). Phosphatase and tensin homologue deleted on chromosome 10 (PTEN) is a phospholipid phosphatase that dephosphorylates phosphatidylinositol 3,4,5triphosphate $(21,22)$ and inhibits PI3K-dependent activation of AKT. The mutation or loss of PTEN leads to constitutively activated AKT. Overexpression of PTEN into PTENdeficient breast, prostate, lung and glial cancer cells resulted in a decrease in activated AKT (23-25). These observations establish AKT as an attractive target for cancer therapy, both alone and in conjunction with standard cancer chemotherapies, as a means of reducing the apoptotic threshold and preferentially killing cancer cells.

Mitochondria are critical death regulators of the intrinsic apoptotic pathway in response to DNA damage, growth factor withdrawal, hypoxia, or oncogene deregulation (26). Second mitochondria-derived activator of caspases (Smac), also known as direct inhibitor of apoptosis protein (IAP) binding protein with low isoelectric point (DIABLO), is a mitochondrial protein containing an $\mathrm{NH}_{2}$-terminal 55-amino-acid mitochondrial import sequence, which is released from mitochondria into the cytosol in response to apoptotic stimuli $(27,28)$. Once released into the cytosol, Smac docks to IAPs within the baculovirus IAP repeat domains via an $\mathrm{NH}_{2}$-terminal motif, thereby eliminating the inhibitory effects of IAPs on caspase-3, caspase-7, and caspase-9 (29). In addition, the interaction of Smac with IAPs results in a rapid ubiquitination and subsequent degradation of released Smac, which is mediated by the ubiquitin-protein ligase (E3) function of some IAPs $(27,30,31)$. Recent studies have shown that mitochondrial Smac release is suppressed by Bcl-2, Bcl- $\mathrm{X}_{\mathrm{L}}$ and AKT, but promoted by Bax, Bad, and Bid $(27,30,32,33)$.

TP53 is the most frequently mutated gene in human cancer (34). The TP53 gene product, p53, is a key regulator of the cellular response to stress and is rapidly up-regulated in response to DNA-damaging agents (34). p53 levels are primarily controlled by the proto-oncoprotein mouse double minute 2 (MDM2), which ubiquitinates p53 and facilitates its proteasomal degradation $(35,36)$. Stabilization and activation of p53 occur through its site-specific phosphorylation, which attenuates the binding of MDM2 to p53 and facilitates the interaction of p53 with coactivators, such as p300, which increase affinity of p53 for consensus DNA sequences within the promoter region of p53-responsive genes (37-39). It is well known that 553 regulates transactivation of a multitude of proapoptotic genes that encode proteins for $\mathrm{BH} 3$-only proteins of the Bcl-2 family, death receptors, and other factors involved in different steps of the apoptotic pathway. p53 can also regulate apoptosis by transcriptional repression of Bcl-2 and IAPs (inhibitor of apoptosis protein) (40). In addition, p53 has an extranuclear role to regulate transcription-independent apoptosis. The extranuclear p53 can directly activate $\mathrm{Bax}$ (41) or directly binds to $\mathrm{Bcl}-\mathrm{X}_{\mathrm{L}}$ and Bcl-2 proteins to induce mitochondrial permeabilization and release cytochrome c (42). Furthermore, expression of the p53-inducible, BH3-only death protein PUMA can displace p53 from $\mathrm{Bcl}-\mathrm{X}_{\mathrm{L}}$, allowing p53 to facilitate activation of Bax with mitochondrial permeabilization (43). The p53responsive genes such as Bax, Bok, Noxa, Puma, Apaf1, and p53AIP1 (44-46) can promote caspase-3 activation by induction of the mitochondria-dependent intrinsic apoptotic pathway. The molecular mechanisms by which curcumin regulates Bcl-2 family members and p53 at the level of mitochondrial are not well understood.

The objectives of our study were to examine the molecular mechanisms by which curcumin regulates the function of proteins acting at the level of mitochondria and to examine the link between PI3K/AKT pathway and mitochondrial events leading to apoptosis. In the current study, we show that curcumin induces apoptosis through regulation of Bcl-2 family members and mitochondrial release of Smac/ DIABLO, cytochrome c and Omi/HtrA2. Moreover, we show that p53 can directly facilitate Smac/DIABLO release at the level of mitochondria and that AKT can inhibit the mitochondrial release of proapoptotic protein Smac, which facilitate caspase-dependent apoptosis, in part, by blocking mitochondrial p53 accumulation. Furthermore, curcumin inhibits PI3K/AKT pathway to promote apoptosis by enhancing the permeabilization of mitochondrial outer membrane and release of mitochondrial proteins to cytosol.

\section{Materials and methods}

Reagents. Antibodies against Bcl-2, Bax, Bak, PI3K/p110, Omi/HtrA2, and B-actin were purchased from Santa Cruz Biotechnology Inc. (Santa Cruz, CA). Anti-cytochrome c, anti-p53, anti-Smac/DIABLO, fluorescein isothiocyanate (FITC)-conjugated anti-caspase-3, and FITC-conjugated antiPARP antibodies were purchased from BD Biosciences/ Pharmingen (San Diego, CA). Anti PI3K/p85 antibody was purchased from Cell Signaling Technology (Beverly, MA). JC-1, and 5-(and-6)-chloromethyl-2',7'-dichlorodihydrofluorescein diacetate, acetyl ester (CM- $\mathrm{H}_{2}$ DCFDA) were purchased from Invitrogen/Molecular Probes, Inc. (Eugene, OR). Enhanced chemiluminescence (ECL) Western blot detection reagents were from Amersham Life Sciences Inc. (Arlington Heights, IL). Antibodies against phospho AKT (Serine 473) and AKT were from New England Biolab. (Ipswich, MA). Smac siRNA and control plasmids were purchased from Imgenex (San Diego, CA). Wortmannin, LY294002, AKT inhibitor, N-acetylcysteine (NAC), Terminal Deoxynucleotidyl Transferase Biotin-dUTP Nick End Labeling 
(TUNEL) assay kit and caspase-3 activity kit were purchased from EMD Biosciences/Calbiochem (San Diego, CA). Curcumin was purchased from LKT Laboratories, Inc. (St. Paul, MN). Smac-N7 peptide (H-AVPIAQK-P-RQIKIWFQN RRMKWKK-OH) and control peptide (H-MKSDFYF-PRQIKIWFQNRRMKWKK-OH) were modified to be cell permeable by linking the lysine carboxyl terminal to the arginine of Antennapedia homeodomain 16-mer peptide (underlined) via a proline linker. All other chemicals used were of analytical grade and were purchased from Fisher Scientific (Suwanee, GA) or Sigma (St. Louis, MO). The expression vectors encoding wild-type PTEN and mutant PTEN were kindly provided by Dr W. Sellers (Harvard Medical School, Boston, MA), whereas WT-AKT, CA-AKT and DNAKT were from Upstate Biotechnology (Lake Placid, NY).

Cell culture. LNCaP, DU145, and PC3 cells were obtained from the American Type Culture Collection (Manassas, VA) and cultured in RPMI-1640 supplemented with $10 \%$ fetal bovine serum (FBS) and 1\% antibiotic-antimycotic (Invitrogen) at $37^{\circ} \mathrm{C}$ in a humidified atmosphere of $95 \%$ air and $5 \% \mathrm{CO}_{2}$. Normal human prostate epithelial cells (PrECs) were purchased from Clonetics/Bio Whittaker (Walkersville, MD), and cultured in PrEBM medium (Cambrex, Rockland, ME). For biochemical analyses, cells were collected by rinsing in phosphate-buffered saline (PBS) thrice, scraping with a rubber policeman in 10-ml PBS, and then centrifuging at $700 \mathrm{~g}$ for $5 \mathrm{~min}$. After removing the PBS, the cell pellets were either used immediately or stored at $-80^{\circ} \mathrm{C}$ until use.

XTT assay. Cells $\left(1 \times 10^{4}\right.$ in $200 \mu 1$ culture medium per well) were seeded in 96-well plate (flat bottom), treated with or without drugs and incubated for various time points at $37^{\circ} \mathrm{C}$ and $5 \% \mathrm{CO}_{2}$. Before the end of the experiment, $50 \mu 1 \mathrm{XTT}$ labeling mixture [final concentration, $125 \mu \mathrm{M}$ XTT (sodium 2,3-Bis(2-methoxy-4-nitro-5-sulfophenyl)-2H-tetrazolium5-carboxanilide inner salt] and $25 \mu \mathrm{M}$ PMS (phenazine methosulphate) per well was added and plates were incubated for further $4 \mathrm{~h}$ at $37^{\circ} \mathrm{C}$ and $5 \% \mathrm{CO}_{2}$. The spectrophotometric absorbance of the sample was measured using a microtitre plate (ELISA) reader. The wavelength to measure absorbance of the formazan product was $450 \mathrm{~nm}$, and the reference wavelength was $650 \mathrm{~nm}$. Growth inhibition was calculated by the following formula: cytostasis $(\%)=[1-(\mathrm{A} / \mathrm{B})] \times 100$, where $\mathrm{A}$ is the absorbance of treated cells, and $\mathrm{B}$ is the absorbance of control cells.

Soft agar assay. Prostate cancer cells $\left(2 \times 10^{4}\right.$ cells/well) were seeded in 12-well culture dishes in RPMI/0.35\% bacto-agar over a bottom layer of RPMI/0.6\% bacto-agar. Cells were then fed with growth media (100-200 $\mu \mathrm{l} /$ well) once a week until colonies grew to a suitable size for observation (about 3 weeks). Number of colonies were counted after they were stained with 3-(4,5-dimethylthiazol-2-yl)-2,5-diphenyltetrazolium bromide $(1 \mathrm{mg} / \mathrm{ml}, 100 \mu \mathrm{l} /$ well $)$ overnight for better visualization.

Transient transfection. Cells were plated in 60-mm dishes in RPMI-1640 containing $10 \%$ FBS and $1 \%$ penicillinstreptomycin mixture at a density of $1 \times 10^{6}$ cells/dish. The next day transfection mixtures were prepared. Cells were transfected with expression constructs encoding wild-type PTEN (pSG5L-HA-PTENwt), mutant PTEN (pSG5L-HAPTEN-G 129E and pSGL5-HA-PTEN-G 129R), wild-typeAKT (pUSE-WT-AKT), constitutively active-AKT (pUSECA-AKT), dominant negative-AKT (pUSE-DN-AKT), or the corresponding empty vectors (pSG5L or pUSE) in the presence of an expression vector pCMV-LacZ (Invitrogen Life Technologies) expressing $\beta$-galactosidase. For each transfection, $2 \mu \mathrm{g}$ of DNA was diluted into $50 \mu 1$ of medium without serum. After the addition of $3 \mu 1$ of Lipofectamine (Invitrogen Life Technologies) into $50 \mu 1$ Opti-MEM medium, the transfection mixture was incubated for $10 \mathrm{~min}$ at room temperature. Cells were washed with serum-free medium, the transfection mixture was added, and cultures were incubated for $24 \mathrm{~h}$ in the incubator. The next day, culture medium was replaced with fresh RPMI-1640 containing 10\% FBS and 1\% penicillin-streptomycin mixture and curcumin was added for desired times. At the end of incubation, cells were washed with ice-cold PBS and lysed in RIPA buffer. Expression of PTEN forms was confirmed by immunoblot analysis with antibodies against the hemagglutinin (HA) epitope encoded for by the expression construct.

For Smac experiment, LNCaP cells were transfected with either plasmid expressing Smac siRNA or control plasmid in the presence of an expression vector PCMV-LacZ (Invitrogen Life Technologies) expressing B-galactosidase. The other details are mentioned above.

Measurement of apoptosis. Cell samples were prepared and

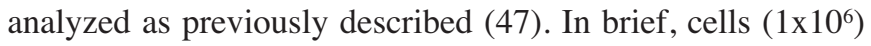
were washed with PBS and fixed with $70 \%$ ethanol for $30 \mathrm{~min}$. After washing with PBS, the cells were stained in $500 \mu 1$ of propidium iodide (PI) staining solution $(33 \mu \mathrm{g} / \mathrm{ml} \mathrm{PI}$, $200 \mu \mathrm{g} / \mathrm{ml}$ DNase-free RNase A, and 0.2\% Triton X-100) overnight at $4{ }^{\circ} \mathrm{C}$. Both cell cycle distribution and apoptosis were measured by a Becton-Dickinson FACScan flow cytometer (San Jose, CA) using 488-nm laser excitation.

Alternatively, apoptosis was measured by the terminal deoxynucleotidyl transferase-mediated nick end-labeling method, which examines DNA strand breaks during apoptosis. Briefly, $1 \times 10^{5}$ cells were treated with curcumin at the indicated doses for various time points at $37^{\circ} \mathrm{C}$. Thereafter, cells were washed with PBS, air-dried, fixed with $4 \%$ paraformaldehyde, and then permeabilized with $0.1 \%$ Triton $\mathrm{X}-100$ in $0.1 \%$ sodium citrate. After washing, cells were incubated with reaction mixture for $60 \mathrm{~min}$ at $37^{\circ} \mathrm{C}$. Stained cells were mounted and analyzed under a fluorescence Olympus microscope (Olympus America Inc., Melville, NY). Pictures were captured using a Photometrics Coolsnap CF color camera (Olympus) and SPOT software (Diagnostic Instruments Inc., Sterling Heights, MI). In some cases, the data were confirmed by staining cells with Hoechst 33248 as previously described. Cells were counted in blinded manner to avoid experimental bias.

Caspase- 3 assay. Cells $\left(3 \times 10^{4}\right.$ per well) were seeded in a 96-well plate with $200 \mu \mathrm{l}$ culture medium. Approximately $16 \mathrm{~h}$ later, cells were treated with various doses of curcumin to induce apoptosis. Casapse-3 activity was measured as per 
manufacturer's instructions (EMD Biosciences) with a fluorometer.

Cellular fractionation. Purified mitochondrial preparations were done as we described elsewhere (33). In brief, cell pelletes were resuspended in ice-cold buffer A $(250 \mathrm{mM}$ sucrose, $20 \mathrm{mM}$ HEPES, $10 \mathrm{mM} \mathrm{KCl}, 1.5 \mathrm{mM} \mathrm{MgCl} 2,1 \mathrm{mM}$ EDTA, $1 \mathrm{mM}$ EGTA, $1 \mathrm{mM}$ DTT, $17 \mu \mathrm{g} / \mathrm{ml}$ phenylmethylsulfonyl fluoride, $8 \mu \mathrm{g} / \mathrm{ml}$ aprotinin, $2 \mu \mathrm{g} / \mathrm{ml}$ leupeptin, $\mathrm{pH}$ 7.4). Cells were homogenize with either 20 strokes of a Dounce homogenizer or 23-gauge needles on ice, and the suspension was centrifuged at $750 \mathrm{x}$ g for $10 \mathrm{~min}$ at $4^{\circ} \mathrm{C}$ to remove nuclei. The supernatant was spun at $10,000 \times \mathrm{g}$ for $25 \mathrm{~min}$ at $40^{\circ} \mathrm{C}$, and the resulting mitochondrial pellets were layered over a 1-2 mM sucrose step gradient [10 mM Tris (pH 7.6), 5 mM EDTA, 2 mM DTT, and $1 \mathrm{X}$ protease inhibitor cocktail] and centrifuged at 22,000 x g for $30 \mathrm{~min}$ at $40^{\circ} \mathrm{C}$. Mitochondria were collected at the 1-1.5 M interphase. The supernatant from the previous step was spun at $100,000 \mathrm{x} \mathrm{g}$ for $30 \mathrm{~min}$ to obtain the cytoplasmic S100. The protein concentrations were determined by Bradford method (Bio-Rad, Hercules, CA). The purification of S-100 protein was determined by Western blot analysis using anticytochrome oxidase 2 antibody.

Western blot analysis. Cell pellets were lysed in RIPA buffer containing $1 \mathrm{X}$ protease inhibitor cocktail, and protein concentrations were determined using the Bradford assay (Bio-Rad, Philadelphia, PA). Cell lysates (20-50 $\mu \mathrm{g}$ ) were electrophoresed in $12.5 \%$ SDS polyacrylamide gels and then transferred onto nitrocellulose membranes. After blotting in $5 \%$ non-fat dry milk in TBS, the membranes were incubated with primary antibodies at 1:1,000 dilution in TBS-Tween-20 overnight at $4^{\circ} \mathrm{C}$, and then secondary antibodies conjugated with horseradish peroxidase at 1:5,000 dilution in TBSTween-20 for $1 \mathrm{~h}$ at room temperature. Protein bands were visualized on X-ray film using an enhanced chemiluminescence system.

Reverse transcription reaction, cDNA synthesis, and PCR. The RT-PCR assay was performed as per the manufacturer's instructions (Access RT-PCR System, Promega, Madison, WI). The primer sequences are as follows: Puma forward, 5'CAGACTGTGAATCCTGTGCT-3', reverse 5'-ACAGTA TCTTACAGGCTGGG-3'; Noxa forward, 5'-GTGCCCTT GGAAACGGAAGA-3', reverse, 5'-CCAGCCGCCCAG TCTAATCA-3'; Bak forward, 5'-AGAGCTGTCTGA ACTCACGT-3', reverse, 5'-TTACACTGTGCCAGAG CCAT-3'; Bim forward, $5^{\prime}-{ }^{\circ} \mathrm{C}$ ATGAGAAGATCCTC CCTGCT-3'; reverse 5'-AATGCATTCTCCACACCAGG-3'; Bax forward 5'-AAGAAGCTGAGCGAGTGT-3', reverse 5'-GGAGGAAGTCCAATGTC-3'; Bcl-X $\mathrm{X}_{\mathrm{L}}$ forward 5'-GCT GGAGTCAGTTTAGTGATGTGGAA-3', reverse 5'-GTGG AGCTGGGATGTCAGGTC-3'; and GAPDH forward 5'-TC TGCCCCCTCTGCTGATGC-3', reverse 5'-CCACCAC CCTGTTGCTGTAG-3'. The PCR was performed for 35 cycles consisting of the following steps: denaturation at $94^{\circ} \mathrm{C}$ for $1 \mathrm{~min}$; annealing at $66^{\circ} \mathrm{C}$ for $1 \mathrm{~min}$; and extension at $72^{\circ} \mathrm{C}$ for $2 \mathrm{~min}$. Both gel analysis and a second PCR reaction amplifying the glyceraldehyde-3-phosphate dehydrogenase housekeeping gene were used to assess mRNA integrity. Internal negative control reactions for the RT-PCR were performed using all of the reagents as for the experimental samples, but with lymphoblast RNA in each of the assays. None of the assays exhibited a signal from the internal negative control.

Measurement of mitochondrial membrane potential $\left(\Delta \Psi_{m}\right)$. Mitochondrial energization was determined by retention of JC-1 dye (Molecular Probes Inc., Eugene) as we described earlier $(33,48)$. Briefly, drug treated cells $\left(5 \times 10^{5}\right)$ were loaded with $\mathrm{JC}-1$ dye $(1 \mu \mathrm{g} / \mathrm{ml})$ during the last $30 \mathrm{~min}$ of incubation at $37^{\circ} \mathrm{C}$ in a $5 \% \mathrm{CO}_{2}$ incubator. Cells were washed in PBS twice. Fluorescence was monitored in a fluorometer using 570-nm excitation/595-nm emission for the J-aggregate of JC1 (49). $\Delta \Psi_{\mathrm{m}}$ was calculated as a ratio of the fluorescence of J-aggregate (aqueous phase) and monomer (membranebound) forms of JC1. Alternatively, mitochondrial membrane potential was also measured by fluorescence microscopy.

Determination of reactive oxygen species (ROS). LNCaP cells were seeded in 96-well plates. After $16 \mathrm{~h}$, cells were loaded with $5 \mu \mathrm{M}$ CM-H2DCFDA dye for $30 \mathrm{~min}$, and treated with either curcumin $(10$ or $20 \mu \mathrm{M})$ or $0.05 \%$ DMSO for 0-360 $\mathrm{min}$. Fluorescence was measured at excitation wavelength of $488 \mathrm{~nm}$ and emission wavelength of $515 \mathrm{~nm}$ using a fluorescence plate reader.

Immunocytochemistry. Cells were grown on fibronectin-coated coverslips (Beckton-Dickinson, Bedford, MA), washed in PBS, and fixed for $15 \mathrm{~min}$ in $4 \%$ paraformaldehyde. Cells were permeabilized in $0.1 \%$ Triton $\mathrm{X}-100$, washed and blocked in $10 \%$ normal goat serum. Cells were incubated with anti-cytochrome c or anti-p53 antibody (1:200) for $18 \mathrm{~h}$ at $4{ }^{\circ} \mathrm{C}$. Cells were then washed and incubated with fluorescently labeled secondary antibodies (1:200) along with DAPI $(1 \mu \mathrm{g} / \mathrm{ml})$ for $1 \mathrm{~h}$ at room temperature. Cells were washed and coverslips were mounted using Vectashield (Vector Laboratories, Burlington, CA). Isotype-specific negative controls were included with each staining. Stained cells were mounted and visualized under a fluorescence Olympus microscope (Olympus America Inc.). Pictures were captured using a Photometrics Coolsnap CF color camera (Olympus) and SPOT software (Diagnostic Instruments Inc.).

Statistical analysis. All data were presented as mean \pm SD from at least three sets of independent experiments. ANOVA analysis with Tukey's multiple comparisons was used to determine the significance of statistical differences between data at the level of $\mathrm{P}<0.05$ using SPSS computer statistics software (SPSS, Inc., Chicago, IL).

\section{Results}

Curcumin inhibits cell viability and colony growth in prostate cancer cells but not in normal prostate epithelial cells. We first measured the effects of curcumin on cell viability in prostate normal, and cancer cells expressing wild-type (LNCaP) and mutated p53 (PC-3, and DU-145). Curcumin has no effect on cell viability of prostate normal epithelial 


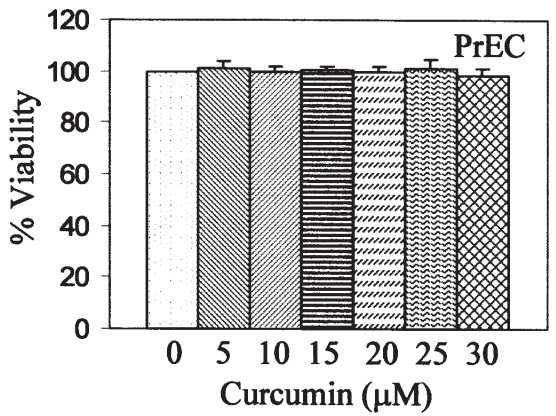

B

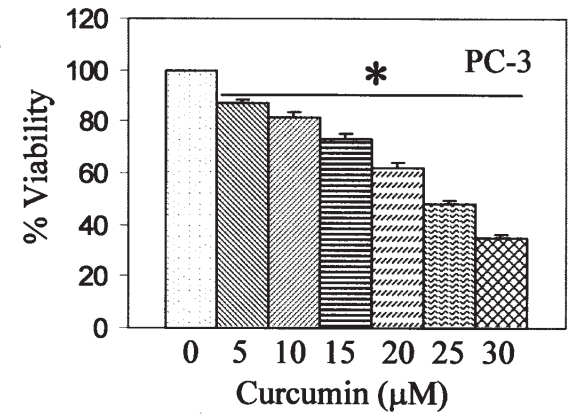

C
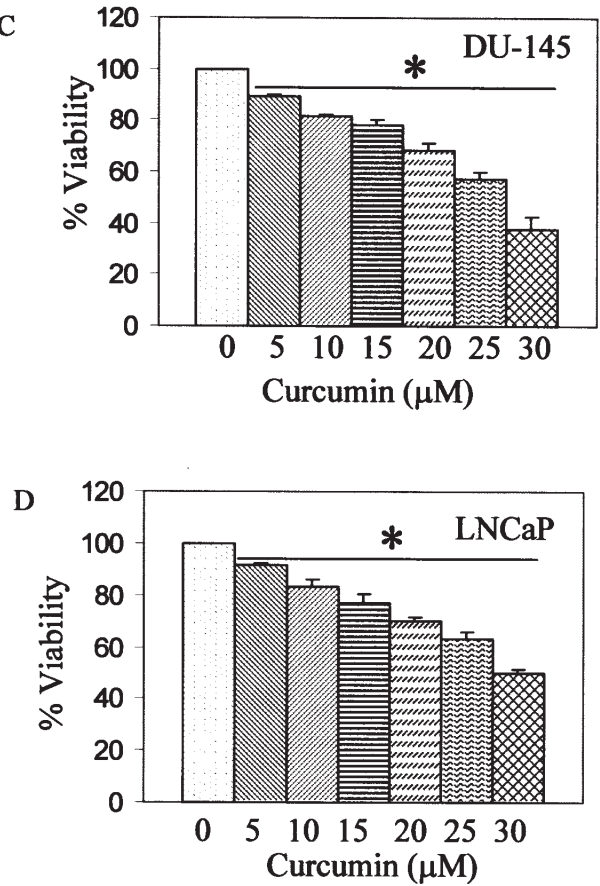

Figure 1. Sensitivity of prostate normal and cancer cells to curcumin. (A) Curcumin has no effect on cell viability of prostate normal epithelial cells (PrECs). Cells were seeded in 96-well plates and treated with curcumin $(0-30 \mu \mathrm{M})$ for $48 \mathrm{~h}$. Cell viability was measured by XTT assay. (B) Curcumin inhibits cell viability in a time-dependent manner in PC-3 cells. Data represent mean \pm SE. *Significantly different from respective control. (C) Curcumin inhibits cell viability in a time-dependent manner in DU-145 cells. Data represent mean \pm SE. *Significantly different from respective control. (D) Curcumin inhibits cell viability in a time-dependent manner in LNCaP cells. Data represent mean \pm SE. ${ }^{*}$ Significantly different from respective control.

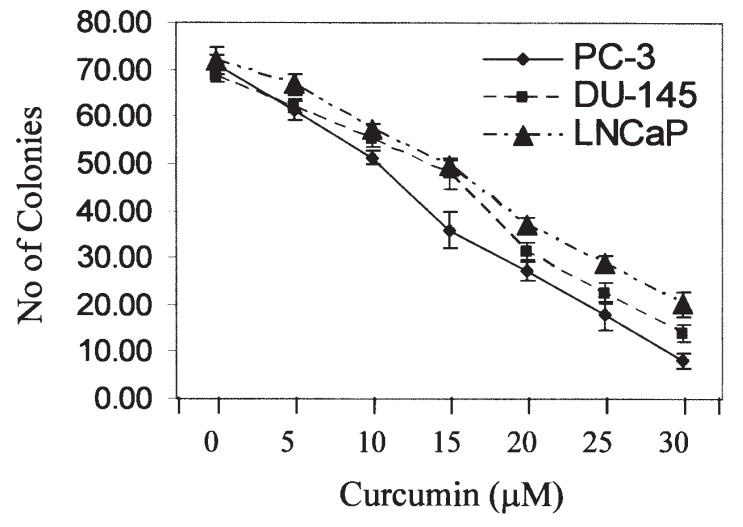

Figure 2. Curcumin inhibits colony growth of prostate cancer cells. Prostate cancer PC-3, DU-145 and LNCaP cells were seeded in soft agar and treated with or without curcumin $(5-30 \mu \mathrm{M})$. After 3 weeks, no of colonies were counted. Data represent mean $\pm \mathrm{SE}$.

cells at $48 \mathrm{~h}$ (Fig. 1A). By comparison, curcumin (0-30 $\mu \mathrm{M})$ inhibited cell viability of human prostate cancer PC-3, DU-145 and LNCaP cells (Fig. 1B-D). These data suggest that the biological effects of curcumin are specific to cancer cells, and curcumin kills cells irrespective of their p53 status.

Anchorage independent colony growth is one of the characteristics of cancer cells. We next measured the effects of curcumin on colony growth in soft agar (Fig. 2). Curcumin at doses ranging from 5-30 $\mu \mathrm{M}$ inhibited colony growth of PC-3, DU-145 and LNCaP cells. Colony formed by PC-3 cells were more sensitive to curcumin than those formed by
DU-145 and LNCaP cells. These data suggest that curcumin has ability to inhibit anchorage-dependent and independent growth of prostate cancer cells, but it has no effect on prostate normal epithelial cells.

Curcumin activates caspase-3 and cleaves PARP. Activation of caspase-3 is crucial for mitochondrial-dependent and independent apoptotic pathways. We therefore examined the activation of caspase- 3 by fluorogenic assay in PC-3 and LNCaP cells (Fig. 3A and B). Curcumin induced caspase-3 activity in both PC-3 and LNCaP cells in a dose-dependent manner. A pan-caspase inhibitor (z-VAD-fmk) blocked curcumin induced caspase- 3 activation in both the cells lines. These data suggest that curcumin-induced apoptosis requires caspase- 3 activation.

We have previously shown that the activation of caspase- 3 by stress stimuli leads to cleavage of several substrates including Poly-ADP Ribose Polymerase (PARP) $(47,50-52)$. We therefore examined the activation of caspase- 3 and cleavage of PARP by immunofluorescence technique (Fig. 3C and D). We have used antibodies that recognize active caspase-3 (Fig. 3C) or cleave PARP (Fig. 3D). Curcumin induced activation of caspase-3 (green fluorescence) and cleavage of PARP (red fluorescence). In apoptotic cells, traslocation of caspase-3 to nucleus was observed.

Curcumin regulates expression of Bcl-2 family members. The $\mathrm{Bcl}-2$ protein family consists of both pro- (e.g. Bax, Bad, $\mathrm{Bid}, \mathrm{Bim})$ and anti-apoptotic (e.g. Bcl-2, Bcl- $\mathrm{X}_{\mathrm{L}}$ ) proteins that regulate mitochondrial outer membrane integrity, cytochrome c release, caspase activation and apoptosis (53-55). 

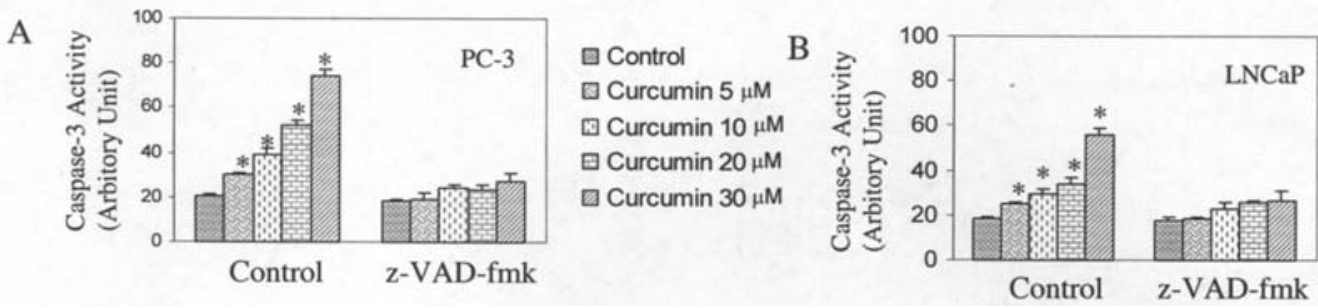

$\square$ Control

口 Curcumin $5 \mu \mathrm{M}$

ㄷ. Curcumin $10 \mu \mathrm{M}$

曰 Curcumin $20 \mu \mathrm{M}$

믄 Cumin $30 \mu \mathrm{M}$
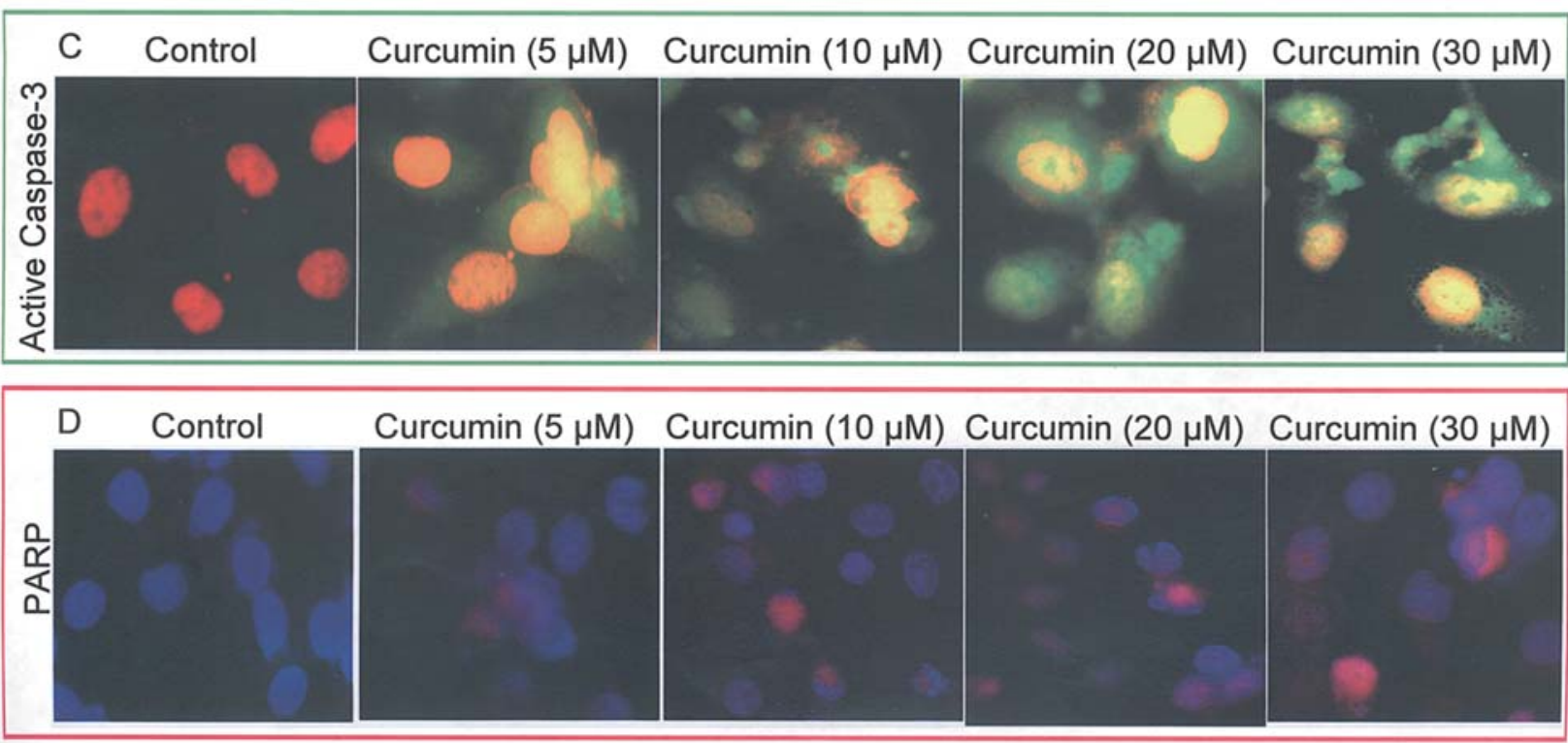

Figure 3. Curcumin induces caspase-3 activity and PARP cleavage. (A and B) Prostate cancer PC-3 and LNCaP cells were pretreated with $25 \mu \mathrm{M}$ pan-caspase inhibitor z-VAD-fmk (z-Val-Ala-Asp-fluoromethylketone) for $2 \mathrm{~h}$, and treated with or without curcumin $(5-30 \mu \mathrm{M})$ for $24 \mathrm{~h}$. Casapse-3 activity was measured by fluorogenic assay as per manufacturer's instruction. Data represent mean \pm SE. (C) Curcumin induces caspase- 3 activity as measured by immunofluorescence microscopy. LNCaP cells were seeded in chambered slides and treated with or without curcumin $(5-30 \mu \mathrm{M})$ for $24 \mathrm{~h}$. Cells were fixed, permeabilized, and stained with propidium iodide (for nuclear staining) and FITC-conjugated anti-active caspase-3 antibody. Red color, nucleus; green color, active caspase-3; yellow color, translocation of caspase-3 to the nucleus. (D) Curcumin induces PARP cleavage as measured by immunofluorescence microscopy. LNCaP cells were seeded in chambered slides and treated with or without curcumin $(5-30 \mu \mathrm{M})$ for $24 \mathrm{~h}$. Cells were fixed, permeabilized, and stained with DAPI (for nuclear staining) and FITC-conjugated anti-PARP antibody, which recognizes cleaved PARP. Blue color, nucleus; red color, cleaved PARP. The green color of FITC was changed to red for better visualization.
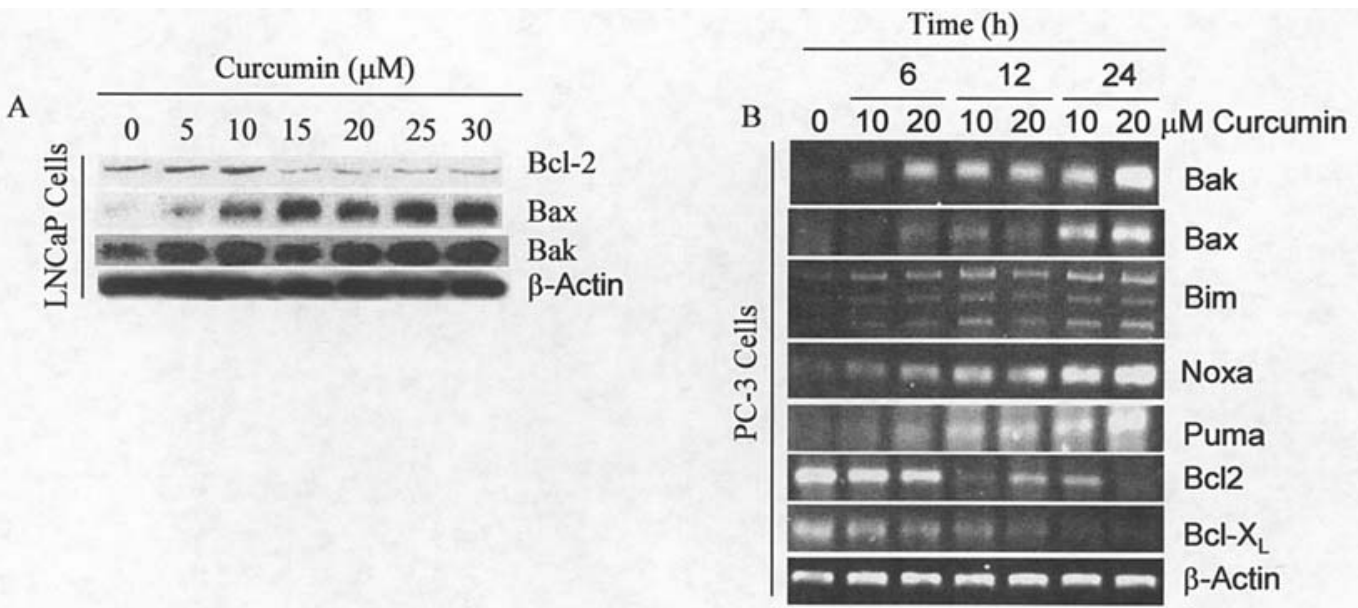

Figure 4. Effects of curcumin on the expressions of Bcl-2 family members in prostate cancer cells. (A) LNCaP cells were treated with or without curcumin (5-30 $\mu \mathrm{M})$ for $48 \mathrm{~h}$. The expressions of Bcl-2, Bax and Bak were examined by the Western blotting. B-actin was used as a loading control. (B) LNCaP cells were treated with or without curcumin $(10$ or $20 \mu \mathrm{M})$ for 6,12 or $24 \mathrm{~h}$. Total RNA was isolated and the expressions of Bak, Bax, Bim, Noxa, Puma, Bcl-2 and Bcl-X $\mathrm{X}_{\mathrm{L}}$ were examined by RT-PCR. B-actin was used as a loading control.

We therefore measured the expression of Bcl-2 family members by Western blotting and RT-PCR (Fig. 4). Western blot analysis revealed the curcumin inhibited the expression of anti-apoptotic protein Bcl-2 and induced the expression of pro-apoptotic proteins Bax and Bak (Fig. 4). RT-PCR analysis demonstrated that curcumin induced expression of 
pro-apoptotic genes Bak, Bax, Bim, Noxa and PUMA, and inhibited expression of anti-apoptotic genes Bcl-2 and Bcl$\mathrm{X}_{\mathrm{L}}$. These data suggest that Bcl-2 family members play major role in curcumin-induced apoptosis in prostate cancer cells.

Curcumin induces changes in mitochondrial functions. During apoptosis, engagement of the mitochondrial pathway involves the permeabilization of the outer mitochondrial membrane (OMM), which leads to the release of cytochrome $\mathrm{c}$ and other apoptogenic proteins such as Smac/DIABLO, AIF, EndoG, Omi/HtraA2 and DDP/TIMM8a (56-59). OMM permeabilization depends on activation, translocation and oligomerization of multidomain Bcl-2 family proteins such as Bax or Bak. We therefore measure the expression of mitochondrial membrane potential, and release of Smac/ DIABLO, cytochrome $\mathrm{c}$ and Omi/HtrA2 from mitochondria to cytosol. Treatment of prostate cancer $\mathrm{LNCaP}$ cells with curcumin resulted in a drop in mitochondrial membrane potential $\left(\Delta \Psi_{\mathrm{m}}\right)$ in time- and dose-dependent manner (Fig. 5A). Curcumin at doses 10-30 $\mu \mathrm{M}$ caused the release of Smac/ DIABLO, cytochrome $\mathrm{c}$ and Omi/HtrA2 from mitochondria to cytosol (Fig. 5B).

Translocation of Bax from cytosol to mitochondria is essential for Bax and Bak oligomerization, and the release of mitochondrial proteins $(33,60,61)$. Besides its well-known action as a transcriptional activator of apoptotic genes, p53 exerts a direct proapoptotic role at the mitochondria via protein-protein interactions with $\mathrm{Bcl}-2$ family members, thus executing the shortest known circuitry of p53 death signaling. Activation of mitochondria-mediated apoptosis represents a major anti-tumor response of p53. One of the mechanisms for p53 to induce mitochondria-mediated cell death events is to activate genes that are directly involved in the initiation of mitochondria-induced apoptosis. Among them are Bcl-2 family members, Noxa, PUMA, and Bax. They have been shown to be direct targets in p53-mediated apoptosis. Cell death induced through the p53 pathway is executed by the caspase proteinases, which, by cleaving their substrates, lead to the characteristic apoptotic phenotype. Caspase activation by $\mathrm{p} 53$ occurs through the release of apoptogenic factors from the mitochondria, including cytochrome c and Smac/ DIABLO. We therefore examine whether curcumin induces translocation of Bax and p53 to mitochondria by preparing mitochondrial fractions. Curcumin at doses $10-30 \mu \mathrm{M}$ induces translocation of Bax and p53 to the mitochondria.

We have previously shown that overexpression of Smac sensitizes TRAIL-resistant cells by regulating IAPs (33). Since curcumin induced Smac/DIABLO release from mitochondria to cytosol, we examined whether of Smac/DIABLO regulates curcumin-induced apoptosis in LNCaP cells. Control peptide had no effect on apoptosis (Fig. 5D). Pretreatment of LNCaP cells with Smac N7 peptide enhanced curcumininduced apoptosis.

We next examined whether inhibition of Smac by siRNA influence curcumin induced apoptosis. LNCaP cells were transiently transfected with either control plasmid or Smac siRNA plasmid in the presence of plasmid (pCMV-LacZ) encoding the $\beta$-galactosidase ( $(-G a l)$ enzyme. Smac siRNA inhibited about $90 \%$ Smac expression (Fig. 5E). The results demonstrated that inhibition of Smac expression by Smac siRNA significantly inhibited curcumin-induced apoptosis (Fig. 5F). These data suggest that mitochondrial protein Smac plays a significant role in curcumin-induced apoptosis.

We next used immunocytochemistry technique to confirm the effects of curcumin on translocation of Bax and p53 to mitochondria, and resultant changes in mitochondrial membrane potential, and cytochrome c release from mitochondria (Fig. 5G). In control cells, Bax and p53 were not colocalized to mitochondria which was clear from distinct red (mitochondria) and green (Bax or p53) color. Treatment of LNCaP cells with curcumin resulted in translocation of Bax and p53 to mitochondria (appearance of yellow mitochondria) in a dose-dependent manner. We next examined the effects of curcumin on mitochondrial membrane potential and cytochrome c release (Fig. 5H). Furthermore, treatment of LNCaP cells with curcumin resulted in drop in mitochondrial membrane potential (change in mitochondrial color from red to green) (Fig. 5I), and cytochrome c release (appearance of red color in the cytoplasm) (Fig. 5J). Interestingly, translocation of Bax and p53 to the mitochondria preceded the drop in mitochondrial membrane potential and cytochrome $\mathrm{c}$ release. These data confirmed the above findings that the curcumin-induced drop in mitochondrial membrane potential and cytochrome c release are due to translocation of Bax and p53 to the mitochondria.

Posttranslation modifications of p53 and histones, and generation of ROS by curcumin. P53 dependent apoptosis has been shown to be mediated by ROS (62). Apoptosis triggered by 53 is dependent on an increase in ROS and the release of apoptotic factors from mitochondrial damage (63). When cells are exposed to stress stimuli, p53 is expressed at high levels by posttranslational modifications, including phosphorylation, acetylation, and glycosylation $(64,65)$. We therefore measure the phosphorylation and acetylation of p53 by curcumin (Fig. 6A). Treatment of LNCaP cells with curcumin at doses ranging from 10 to $30 \mu \mathrm{M}$ resulted in phosphorylation and acetylation of p53 at $4 \mathrm{~h}$. By comparison, curcumin did not induce p53 in LNCaP cells at $4 \mathrm{~h}$ (data not shown). These data suggest that posttranslation mechanisms may play important roles in p53 stabilization and function.

Epigenic changes play important roles in oncogenesis. We and others have shown that the inhibitors of methyltransferases and deacetylases inhibit proliferation and induce apoptosis in cancer cells $(51,55,66)$. Furthermore, hyperacetylation of histones correlates with gene activation, whereas deacetylation mediates eukaryotic chromatin condensation and gene expression silencing. We examined whether curcumin induces acetylation of histones $\mathrm{H} 3$ and $\mathrm{H} 4$. Curcumin at doses ranging from 10 to $30 \mu \mathrm{M}$ caused acetylation of histone $\mathrm{H} 3$ and $\mathrm{H} 4$ at $4 \mathrm{~h}$ in LNCaP cells (Fig. 6A). These data suggest that curcumin may regulate apoptosis through global regulation of genes related to cell survival and/or apoptosis. However, further studies are needed to confirm this hypothesis.

Generation of reactive oxygen species (ROS) by oxidative damage play an important role in apoptosis $(67,68)$. Recent studies have shown that cancer preventive agent induced apoptosis through generation of ROS. We next examined 

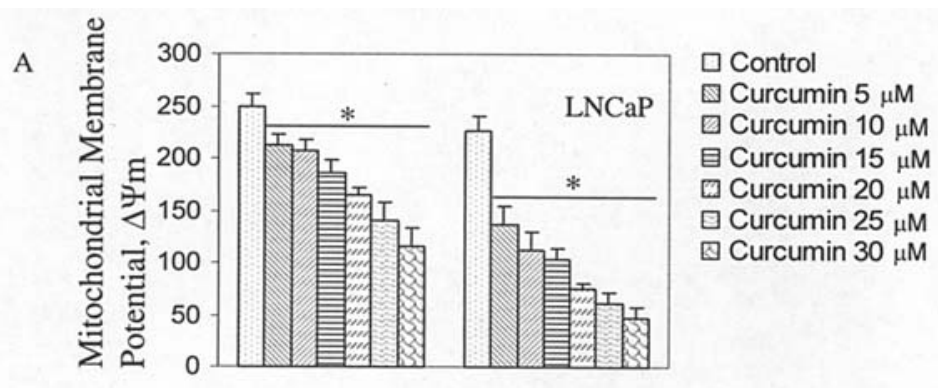

24

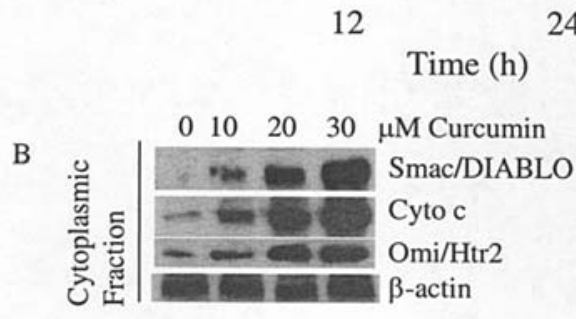

$\begin{array}{llllll}0 & 10 & 20 & 30 & \mu \mathrm{M} \text { Curcumin }\end{array}$
$\mathrm{D}$
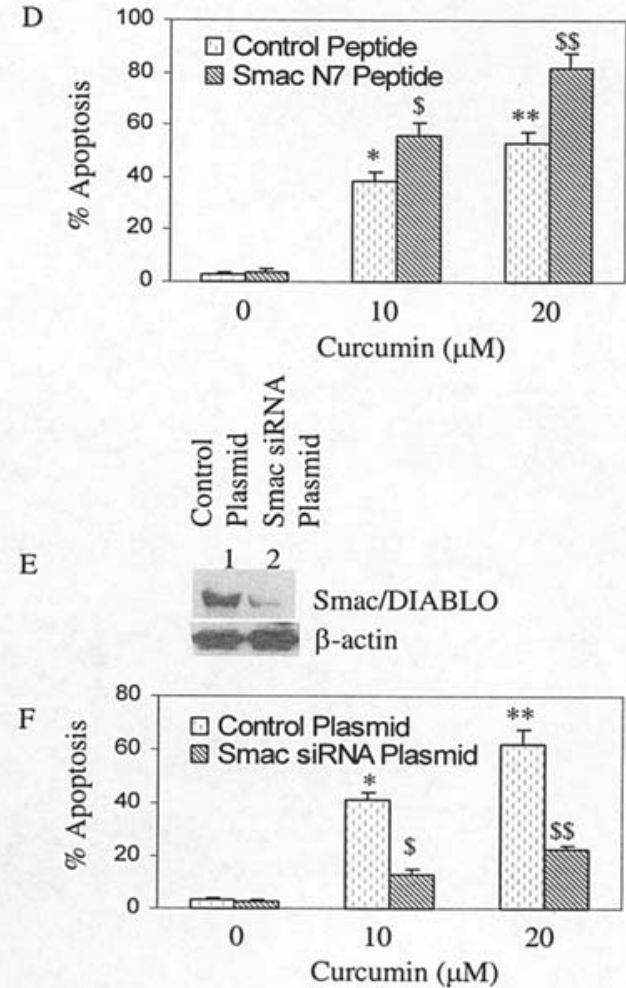

Figure 5. A-F. Effects of curcumin on mitochondrial membrane potential, release of mitochondrial proteins to cytosol, and translocation of Bax and p53 to mitochondria. (A) Curcumin induces drop in mitochondrial membrane potential $\Delta \Psi_{\mathrm{m}}$. LNCaP cells were treated with or without curcumin (5-30 $\left.\mu \mathrm{M}\right)$ for 12 or $24 \mathrm{~h}$. Cells were stained with JC1 dye, and $\Delta \Psi_{\mathrm{m}}$ was measured by a fluorometer as per manufacturer's instructions. (B) LNCaP cells were treated with various doses of curcumin $(0-30 \mu \mathrm{M})$ for $8 \mathrm{~h}$, and cytoplasmic fractions were prepared. Cytoplasmic levels of Smac/DIABLO, Cyto c and Omi/HtrA2 were measured by the Western blot analysis. (C) Curcumin induces translocation of Bax and p53 to the mitochondria. LNCaP cells were treated with curcumin (0-30 $\mu \mathrm{M})$ for $4 \mathrm{~h}$. Mitochondrial fractions were prepared and the expressions of Bax and p53 were measured by the Western blot analysis. Anti-COX IV antibody was used as a loading control. (D) Enhancement of curcumin-induced apoptosis by Smac N 7 peptide. LNCaP cells were pretreated with $25 \mu \mathrm{M}$ control Smac peptide or Smac $\mathrm{N} 7$ peptide for $2 \mathrm{~h}$, and treated with or without curcumin $(10 \mu \mathrm{M})$ for $48 \mathrm{~h}$. Apoptosis was measured by TUNEL assay as per manufacturer's instructions. Data represent mean $\pm \mathrm{SE} .{ }^{*},{ }^{* *}, \$$ and $\$$ were significantly different from respective controls $(\mathrm{P}<0.05)$. (E) Inhibition of curcumin-induced apoptosis by Smac siRNA. LNCaP cells were transiently transfected with either control plasmid or Smac siRNA plasmid in the presence of plasmid (pCMV-LacZ) encoding the ß-galactosidase ( $(-G a l)$ enzyme. There was no difference in transfection efficiency among groups. Cell lysates were sun on SDS-PAGE to measure the expression of Smac/DIABLO by Western blot analysis. (F) LNCaP cells were transiently transfected with either control plasmid or Smac siRNA plasmid in the presence of plasmid (pCMV-LacZ) encoding the ß-galactosidase ( $(-G a l$ ) enzyme. There was no difference in transfection efficiency among groups. After 24 of transfection, cells were treated with or without curcumin $(20 \mu \mathrm{M})$ for $48 \mathrm{~h}$. Apoptosis was measured by TUNEL assay as per manufacturers instructions. Data represent mean $\pm \mathrm{SE} .{ }^{*},{ }^{* *}, \$$ and $\$ \$$ were significantly different from respective controls $(\mathrm{P}<0.05)$.

whether, curcumin causes oxidative stress that is responsible for its apoptotic effect. Pretreatment of LNCaP cells with $50 \mathrm{mM} \mathrm{N}$-acetylcysteine for $15 \mathrm{~min}$ before curcumin (10 or $20 \mu \mathrm{M})$ treatment resulted in a significant reversal of curcumininduced apoptosis (Fig. 6B), which was correlated with a marked reduction in curcumin-induced caspase- 3 activity (Fig. 5C). Since NAC inhibited curcumin-induced caspase-3 activity and apoptosis, we measured ROS production by curcumin (Fig. 6D). The treatment of LNCaP cells with curcumin resulted in ROS production with was sustained for $60 \mathrm{~min}$, after that it declined up to $360 \mathrm{~min}$. Together these results suggest that curcumin-induced apoptosis is also mediated through generation of ROS, which, in turn, activates cell intrinsic pathway of apoptosis.

Treatment of LNCaP cells with curcumin at doses ranging from 10 to $30 \mu \mathrm{M}$ resulted in induction of $\mathrm{p} 53$, and phosphorylation and acetylation of $\mathrm{p} 53$. These data suggest that posttranslation mechanisms may play important roles in p53 stabilization and function.

Curcumin inhibits phosphatidylinositol 3'-kinase (PI3K) and phospho AKT. Drugs targeting the PI3K pathway aim to inhibit proliferation, promote apoptosis, and enhance chemosensitivity and radiosensitivity of cancer cells. The phosphatase and tensin homologue (PTEN) phosphatidylinositol 3'-phosphatase is a key negative regulator of the PI3K pathway. We therefore investigated whether the phos-phati-dylinositol 3-kinase (PI3K)/AKT is involved in the curcumin-induced apoptosis in prostate cancer cells. Curcumin inhibited the expression of p110 and p85 subunits of PI3K in a dosedependent manner (Fig. 7A).

Since AKT is an important regulator of various intracellular events in prostate tumor progression, we explored whether AKT activity is regulated by curcumin. AKT activity 

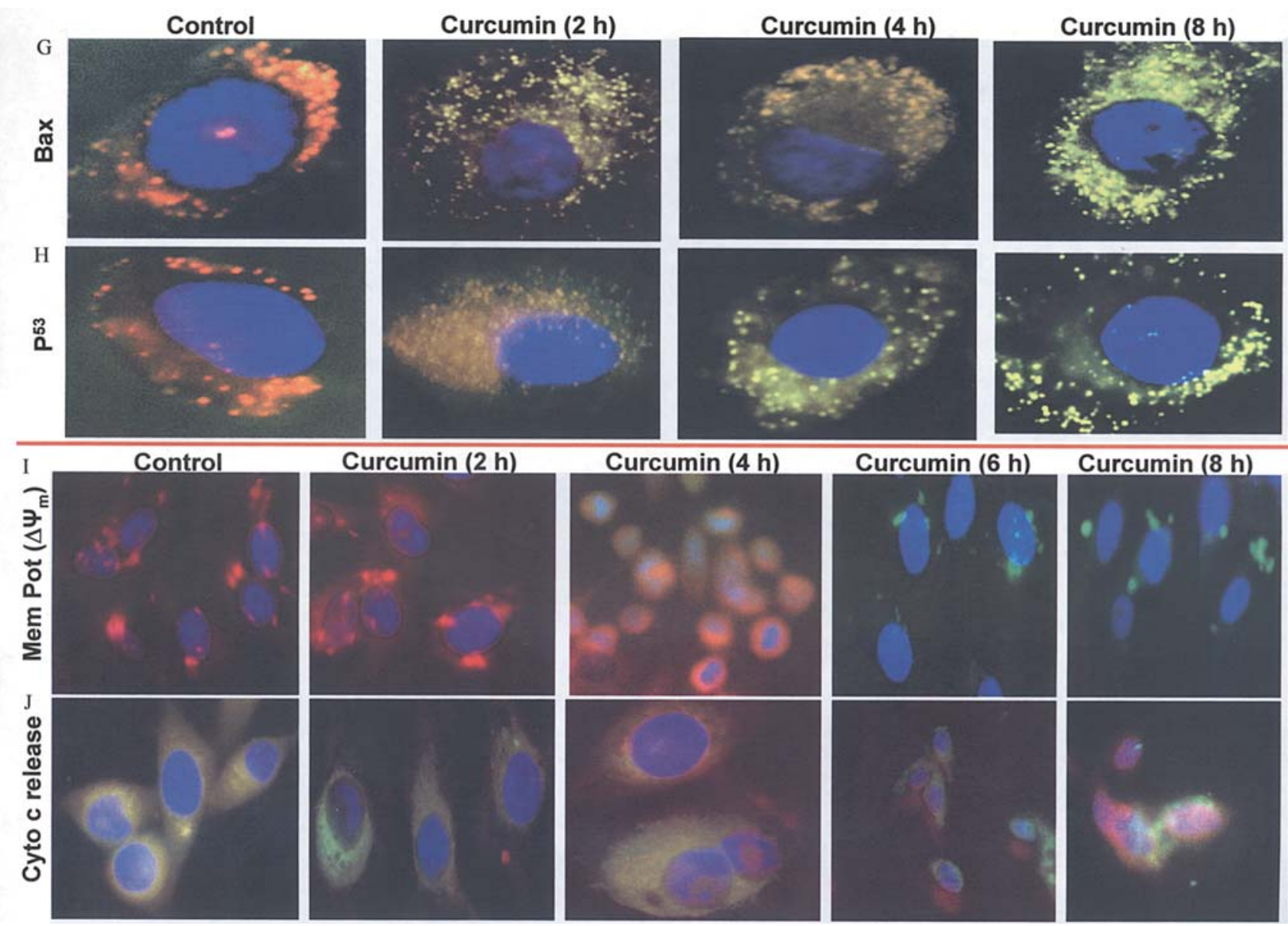

Figure 5. G-I. (G and H) Curcumin induces translocation of Bax and p53 to the mitochondria. Cells were treated with or without curcumin for 2,4 or $8 \mathrm{~h}$. Cells were fixed, permeabilized and stained with anti-Bax or anti-p53 antibody at $4^{\circ} \mathrm{C}$ for $18 \mathrm{~h}$. After washing, cells were stained with mitotracker red (mitochondrial staining), DAPI (nuclear staining) and secondary antibody conjugated with FITC (for Bax or p53). Red color, mitochondria; green color, Bax or p53; blue color, nucleus; yellow, translocation of Bax or p53 to mitochondria. (I) Curcumin induces drop in mitochondrial membrane potential. LNCaP cells were seeded in chambered slides and treated with or without curcumin $(20 \mu \mathrm{M})$ for $2,4,6$ or $8 \mathrm{~h}$. For mitochondrial membrane potential, cells were treated with JC-1 dye and DAPI, and visualized under a fluorescence microscope. Change of red mitochondria to green color is an indication of $\Delta \Psi_{\mathrm{m}}$. In apoptotic cells, the dye remains in its monomeric form and appears green. (J) Curcumin induces cytochrome $\mathrm{c}$ release from mitochondria. LNCaP cells were seeded in chambered slides and treated with or without curcumin $(20 \mu \mathrm{M})$ for 2, 4, 6 or $8 \mathrm{~h}$. Cells were with fixed, permeabilized, and stained with anticytochrome c antibody at $4^{\circ} \mathrm{C}$ for $18 \mathrm{~h}$. After washing, cells were stained with mitotracker green (mitochondrial staining), DAPI (nuclear staining) and secondary antibody conjugated with texas red (for cytochrome c), and visualized under a fluorescence microscope. Green color, mitochondria; red color, cytochrome c; blue color, nucleus; yellow, colocalization of cytochrome $\mathrm{c}$ to mitochondria.

was measured by immunoblotting using phospho-specific Ser ${ }^{473}$ AKT antibody. Data revealed that the phosphorylation of AKT was inhibited by curcumin (5-20 $\mu \mathrm{M})$ (Fig. 7A). These data suggest that inhibition of PI3K/AKT pathway may enhance the sensitivity of prostate cancer cells to curcumin.

Overexpression of PTEN or dominant negative AKT (DN$A K T)$ enhances curcumin-induced apoptosis in LNCaP cells. The tumor suppressor gene PTEN is quite often inactivated in primary human prostate cancers, particularly in the more advanced cancers, and in human prostate cancer xenografts and cell lines. These studies suggest that downstream target of the PI3 kinase pathway such as AKT that is negatively regulated by PTEN, may be increasingly activated with prostate tumor progression. Since LNCaP cells express constitutively active AKT, we sought to examine is the role of PI3K/AKT pathway on curcumin-induced apoptosis. The LNCaP cells were transfected with empty vector or plasmid expressing wild-type PTEN, PTEN-G129E, or PTEN-G129R and incubated in the presence or absence of curcumin (Fig. 7B). Curcumin induced apoptosis in empty vector transfected LNCaP cells. Transfection of LNCaP cells with wild-type PTEN significantly enhanced curcumin induced apoptosis. Overexpression of PTEN-G129E or PTEN-G129R in LNCaP cells significantly inhibited curcumin-induced apoptosis.

Since overexpression of PTEN enhances the apoptosis inducing potential of curcumin, we manipulated AKT expression by wild-type AKT (WT-AKT), constitutively active AKT (CA-AKT) and dominant negative AKT (DNAKT) in LNCaP cells. LNCaP cells were transiently transfected with empty vector, WT-AKT, CA-AKT or DNAKT and treated with or without curcumin $(20 \mu \mathrm{M})$. Transfection of LNCaP cells with empty vector, WT-AKT, CA-AKT or DN-AKT had no effect on apoptosis (Fig. 7C). Curcumin induced apoptosis in vector transfected cells. Overexpression of WT-AKT or CA-AKT in LNCaP cells 

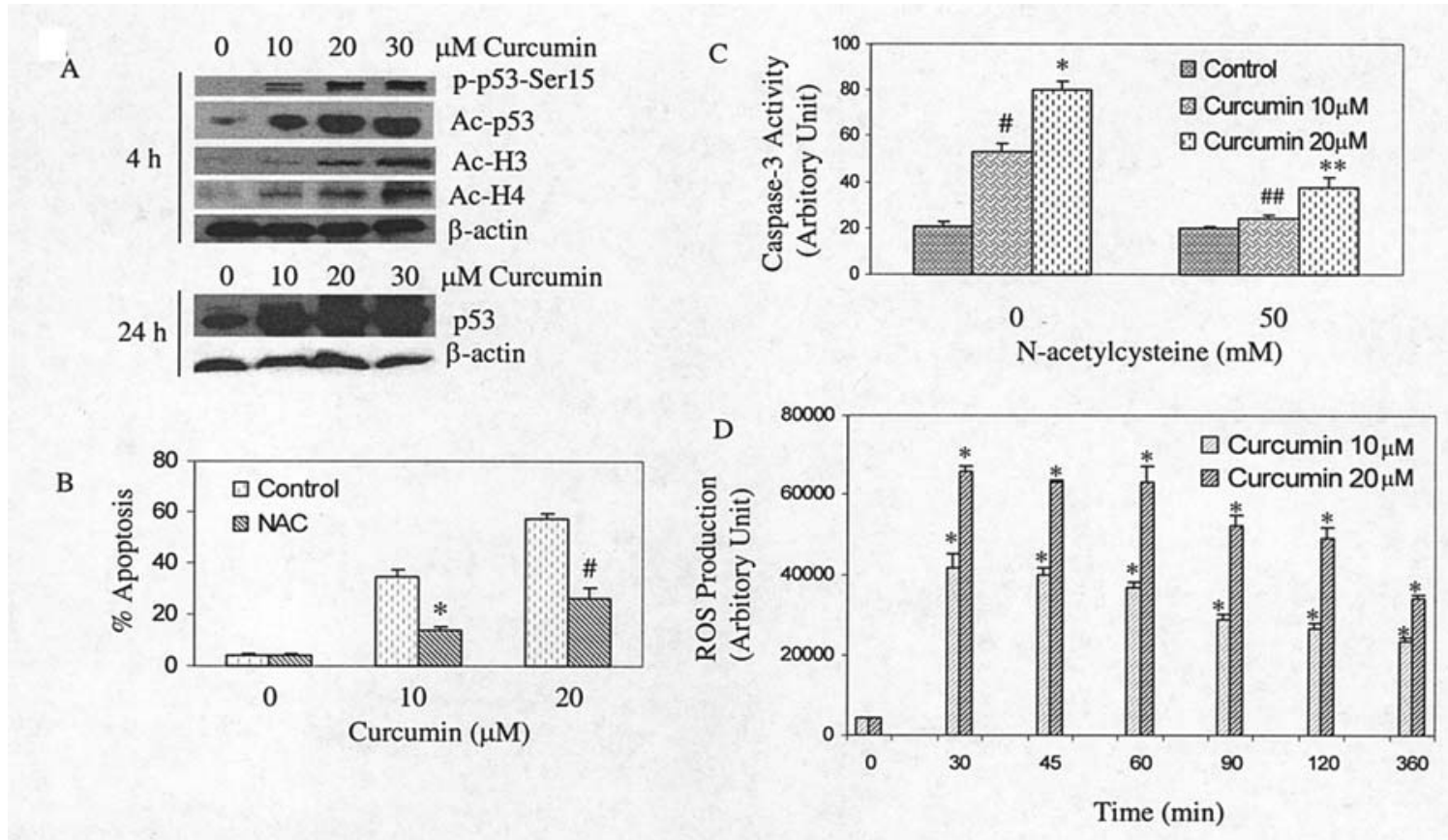

Figure 6. Involvement of p53, histones, and reactive oxygen species in curcumin-induced apoptosis. (A) Effects of curcumin on induction, phosphorylation and acetylation of $\mathrm{p} 53$, and on acetylation of histone $\mathrm{H} 3$ and $\mathrm{H} 4$. LNCaP cells were treated with curcumin for either $4 \mathrm{~h}$ to measure the phosphorylation or acetylation of p53 or $24 \mathrm{~h}$ to measure the induction of p53. Cell lysates were prepared and subjected to the Western blot analysis for the measurement of total p53, phosphorylated form of p53, and acetylated forms of p53, H3 and H4. B-actin was used as a loading control. (B) Inhibition of curcumin-induced apoptosis by $\mathrm{N}$-acetylcysteine (NAC). LNCaP cells were pretreated with $50 \mathrm{mM}$ NAC for $2 \mathrm{~h}$ followed by treatment with 10 or $20 \mu \mathrm{M}$ curcumin for $24 \mathrm{~h}$, and apoptosis was measured by TUNEL assay. *Significantly different from respective controls, $\mathrm{P}<0.05$. (C) Inhibition of curcumin-induced caspase-3 activity by $\mathrm{N}$-acetylcysteine (NAC). LNCaP cells were pretreated with $50 \mathrm{mM} \mathrm{NAC}$ for $2 \mathrm{~h}$ followed by treatment with curcumin (10 or $20 \mu \mathrm{M}$ ) for $12 \mathrm{~h}$, and caspase-3 activity was measured by a fluorometer as per manufacturer's instructions. \# or *significantly different from \#\# or **, respectively, P<0.05. (D) Curcumin induced apoptosis is mediated by ROS. LNCaP cells were seeded in 96-well plates, loaded with $5 \mu \mathrm{M} \mathrm{CM-H2DCFDA} \mathrm{dye} \mathrm{for} 30$ min, and treated with either curcumin $(10$ or $20 \mu \mathrm{M}$ ) or $0.05 \%$ DMSO for 0-360 min. Fluorescence was measured by a fluorometer as per manufacturer's instructions (EMD Biosciences/ Molecular Probes). * Significantly different from respective controls, $\mathrm{P}<0.05$.

inhibited curcumin-induced apo-ptosis; whereas transfection of LNCaP cells with DN-AKT enhanced apoptosis induced by curcumin.

We next examined the effects of pharmacological inhibition of AKT by LY294002, Wortmannin or AKT inhibitor on curcumin-induced apoptosis in LNCaP cells (Fig. 7D). Curcumin induced apoptosis in LNCaP cells. Pretreatment of LNCaP cells with LY294002, Wortmannin or AKT inhibitor significantly enhanced apoptosis induced by curcumin at $48 \mathrm{~h}$. These data suggest that inhibition of AKT activity either by genetic and pharmacological approaches or overexpression of PTEN enhances apoptosis induction due to curcumin treatment.

Since curcumin inhibited viability, induced apoptosis and attenuated PI3K/AKT pathway, we sought to examine whether AKT exerts its effects before or after mitochondrial permeabilization, which causes Smac release from the mitochondria. After transfection of $\mathrm{LNCaP}$ cells with empty vector, CA-AKT or DN-AKT, cells were treated with curcumin for $8 \mathrm{~h}$, and the release of Smac/DIABLO from mitochondria to cytosol was measured by the Western blot analysis (Fig. 7E). Curcumin induced Smac release in vector transfected control group. Overexpression of CA-AKT inhibited curcumininduced Smac release, whereas overexpression of DN-AKT enhanced curcumin-induced Smac release. These data suggest that PI3K/AKT pathway interact with apoptotic pathway at or prior to mitochondrial events.

Since curcumin induced translocation of p53 to mitochondria, we sought to examine whether regulation of AKT by curcumin influences translocation of p53 to mitochondria (Fig. 7F). Curcumin induced translocation of p53 to the mitochondria in empty vector transfected group at $4 \mathrm{~h}$. Overexpression of constitutively active AKT by CA-AKT inhibited curcumin-induced p53 translocation, whereas inhibition of AKT by DN-AKT enhanced translocation of p53 to the mitochondria. These data suggest that AKT blocks apoptosis by regulating mitochondrial events related to apoptosis induction.

\section{Discussion}

In the present study, we have shown that curcumin induced apoptosis in prostate cancer cells through activation of multiple signaling pathways. Curcumin-induced apoptosis engages mitochondria which was evident by drop in mitochondrial membrane potential and the release of cytochrome C, Smac/ DIABLO, and Omi/HtrA2 in prostate cancer cells. Curcumin induced expression of proapoptotic proteins (Bax, Bak, PUMA, Noxa and Bim) and inhibited expression of antiapoptotic proteins $\left(\mathrm{Bcl}-2\right.$ and $\left.\mathrm{Bcl}-\mathrm{X}_{\mathrm{L}}\right)$. These proteins exert their effect mainly at the level of mitochondria. Furthermore, 

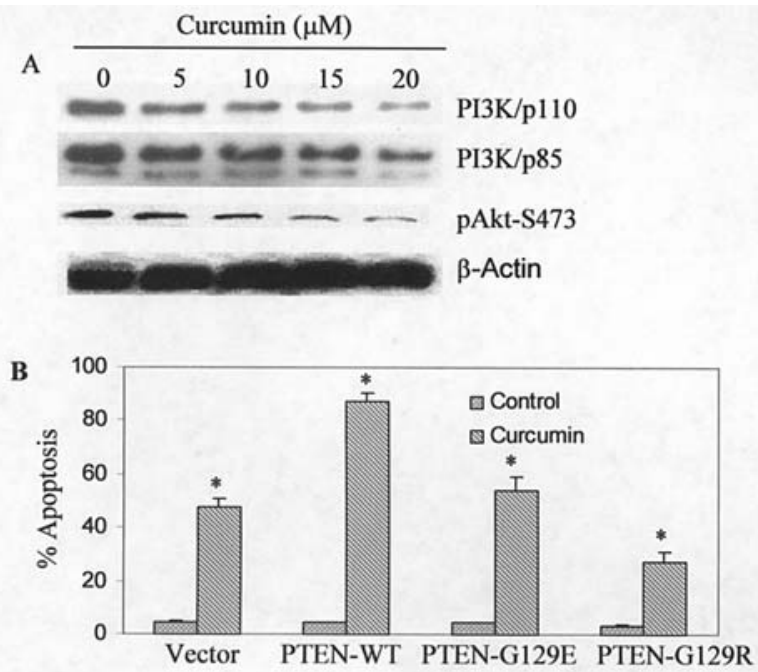

C

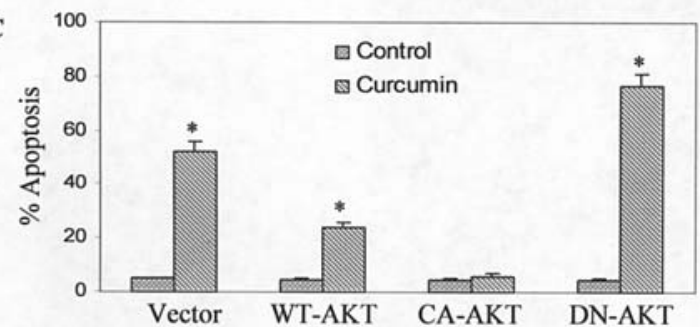

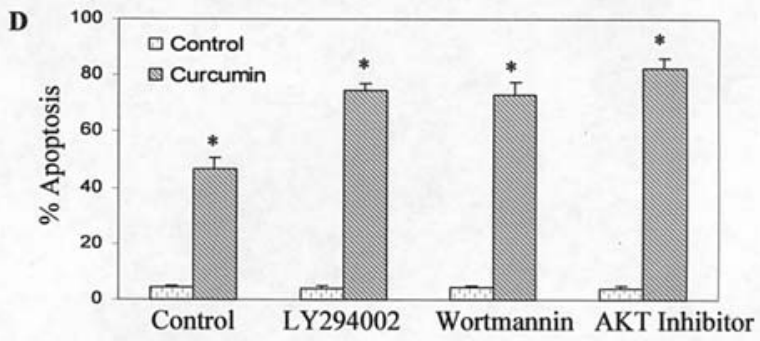
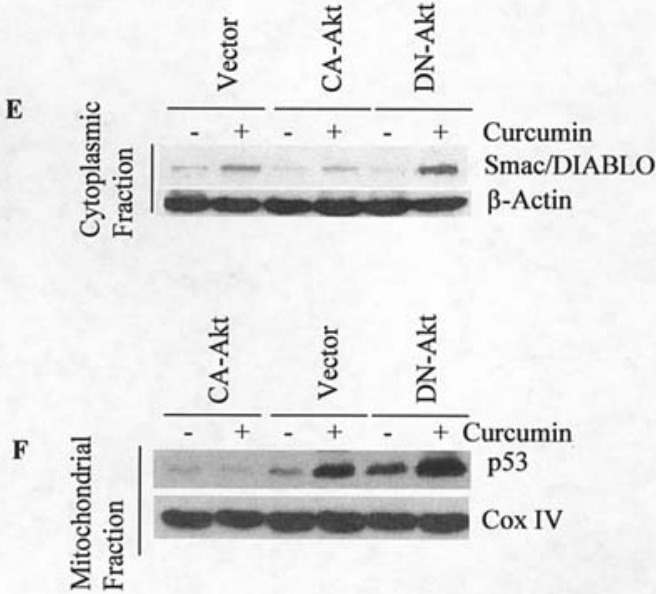

Figure 7. Regulation of PI3K and AKT by curcumin. (A) LNCaP cells were treated with curcumin ( 0 - $20 \mu \mathrm{M})$ for $24 \mathrm{~h}$, and the expression of PI3K subunits (p110 and p85) and phospho-AKT was measured by the Western blot analysis. B-actin was used as a loading control. (B) Effects of PTEN on curcumininduced apoptosis. LNCaP cells were transiently transfected with empty vector, PTEN-WT, PTEN-G129E, or PTEN-G129R mutant in the presence of control plasmid (pCMV-LacZ) encoding the ß-galactosidase ( $(-G a l)$ enzyme. There was no difference in transfection efficiency among groups. Cells were treated with or without curcumin $(20 \mu \mathrm{M})$ for $48 \mathrm{~h}$. Apoptosis was measured by TUNEL assay as per manufacturer's instructions. Data represent mean \pm SE. (C) Effects of AKT on curcumin-induced apoptosis. LNCaP cells were transiently transfected with empty vector, wild-type AKT (WT-AKT), constitutively active AKT (CA-AKT), or dominant negative AKT (DN-AKT) mutant in the presence of control plasmid (pCMV-LacZ) encoding the B-galactosidase (B-Gal) enzyme. There was no difference in transfection efficiency among groups. Cells were treated with or without curcumin (20 $\mu \mathrm{M})$ for $48 \mathrm{~h}$. Apoptosis was measured by TUNEL assay as per manufacturer's instructions. Data represent mean \pm SE. (D) PI3-Kinase inhibitors (20 $\mu$ M LY-294002 and 200 nM Wortmannin) and AKT inhibitor $(2 \mu \mathrm{M})$ enhance curcumin-induced apoptosis. LNCaP cells were treated with $20 \mu \mathrm{M}$ LY-294002, $200 \mathrm{nM}$ Wortmannin, or $2 \mu \mathrm{M}$ AKT inhibitor in the presence or absence of curcumin $(20 \mu \mathrm{M})$ for $48 \mathrm{~h}$, and apoptosis was measured by TUNEL assay. Data represent mean \pm SE. (E) Effects of AKT on curcumin-induced Smac release. LNCaP cells were transiently transfected with empty vector, constitutively active AKT (CA-AKT), or dominant negative AKT (DN-AKT) mutant in the presence of control plasmid (pCMV-LacZ) encoding the B-galactosidase (B-Gal) enzyme. There was no difference in transfection efficiency among groups. After transfection, cells were treated with or without curcumin ( $20 \mu \mathrm{M})$ for $8 \mathrm{~h}$. Smac/DIABLO release in the cytoplasmic fraction was measured by the Western blot analysis. (F) Effects of AKT on curcumin-induced apoptosis. LNCaP cells were transiently transfected with empty vector, constitutively active AKT (CA-AKT), or dominant negative AKT (DN-AKT) mutant in the presence of control plasmid (pCMV-LacZ) encoding the B-galactosidase (B-Gal) enzyme. There was no difference in transfection efficiency among groups. After transfection, cells were treated with or without curcumin $(20 \mu \mathrm{M})$ for $4 \mathrm{~h}$. Mitochondrial translocation of p53 was measured by the Western blot analysis. Anti-Cox IV antibody was used as a loading control.

curcumin enhances translocation of p53 and Bax to mitochondria where these proteins may interact with other Bcl-2 family members to cause permeabilization of outer mitochondrial membrane and release of mitochondrial proteins leading to caspase activation and apoptosis. Moreover, our data show that inhibition of PI3K/AKT pathway enhances the apoptosis inducing potential of curcumin in prostate cancer cells. Interestingly, stabilization of p53 by phosphorylation or acetylation may further enhance the biological effects of p53. Finally, our data suggest that translocation of p53 to the mitochondria is an active process and show that AKT can specifically attenuate this process.

Research over the last decade has extended the prevailing view of mitochondria to include functions well beyond the critical bioenergetics role in supplying ATP. It is now recog- nized that mitochondria play a crucial role in cell signaling events, inter-organelle communication, aging, many diseases, cell proliferation and cell death. Cellular stresses lead to stabilization and activation of the p53 tumor suppressor protein. Depending on the cellular context, this results in one of two different outcomes: cell cycle arrest or apoptotic cell death. Cell death induced through the p53 pathway is executed by the caspases, which, by cleaving their substrates, lead to the characteristic apoptotic phenotype. Caspase activation by p53 occurs through the release of apoptogenic factors from the mitochondria, including cytochrome c, Smac/DIABLO and Omi/HtrA2. Released cytochrome c allows the formation of a high-molecular weight complex, the apoptosome, which consists of the adapter protein Apaf-1 and caspase-9, which is activated following recruitment into 
the apoptosome. Active caspase- 9 then cleaves and activates the effector caspases, such as caspase-3 and -7 , which execute the apoptotic program.

Our data have shown that curcumin causes release of mitochondrial Smac/DIABLO, cytochrome c and Omi/HtrA2. $\mathrm{Smac}$ is released from mitochondria to the cytosol after cellular insults and binds to IAPs (XIAP, survivin, c-IAP-1, or c-IAP-2), and abrogates IAP-mediated inhibition of caspase-3 and caspase-7, thereby facilitating caspase-mediated apoptosis. The release of mitochondrial apoptogenic factors is regulated by the pro- and anti-apoptotic Bcl-2 family proteins, which either induce or prevent the permeabilization of the outer mitochondrial membrane. The mechanism by which p53 signals to the Bcl-2 family proteins is unclear. It was shown that some of the pro-apoptotic family members, such as Bax, Noxa or PUMA, are transcriptional targets of p53. In addition, transcription-independent, pro-apoptotic activities of p53 have been described. The elucidation of the p53-depen-dent pathway, resulting in mitochondrial outer membrane permeabilization through the pro-apoptotic Bcl-2 family proteins, is a key to unveiling the mechanism of stress-induced apoptosis.

We previously showed that TRAIL induces apoptosis in prostate cancer cells through release of cytochrome $\mathrm{c}$ and Smac/DIABLO $(47,48)$, and Bax and Bak differentially regulate the release of cytochrome $\mathrm{c}$ and Smac from mitochondria (33). We have extended these studies to investigate the role of Smac in curcumin-induced apoptosis in prostate cancer cells. In the present study, we found that curcumininduced mitochondrial Smac release was associated with sensitivity of cells to curcumin, suggesting that Smac release may be a determinant of curcumin-induced apoptosis. Furthermore, down-regulation of Smac by RNA interference conferred resistance whereas addition of a Smac-mimetic peptide enhances curcumin-induced apoptosis, suggesting that Smac release is required for efficient curcumin-induced apoptosis. To our knowledge, this represents the first finding that regulation of Smac release by curcumin is an important event for apoptosis induction. However, Smac RNA interference could not completely suppress curcumin-induced apoptosis, suggesting that there may be additional, Smacindependent, mechanisms of curcumin-induced apoptosis. To that end, we also showed that the curcumin also induces mitochondrial release of cytochrome $\mathrm{c}$ and $\mathrm{Omi} / \mathrm{HtrA} 2$ in prostate cancer cells. The release of cytochrome $\mathrm{c}$ and Omi/ HtrA 2 may be required to achieve maximum chemopreventive effects of curcumin.

We and others have shown that mitochondrial Smac release is suppressed by $\mathrm{AKT}, \mathrm{Bcl}-2$, and $\mathrm{Bcl}-\mathrm{XL}$, but promoted by Bax, Bad, and Bid (27,31,33,69-71). Furthermore, AKT inhibits Bid cleavage and Bax activation, thereby inhibiting cytochrome c, Smac, and Omi/HtrA2 release and suppressing apoptosis $(31,33,71)$. Here, we showed that AKT activation by constitutively active AKT attenuated curcumin-induced Smac release and apoptosis whereas inhibition of AKT function by dominant negative AKT facilitated these responses in wt-p53 expressing LNCaP cells. These results confirm that AKT is a determinant of curcumin sensitivity in prostate cancer cells and suggest that regulation of Smac release may be one of the mechanisms of inducing apoptosis.
Although AKT has been shown to affect nuclear p53 function, the current study provides strong evidence that AKT may serve a more wide-ranging antiapoptotic role by interfering with the mitochondrial accumulation of p53. Our data show that AKT activation by constitutively active AKT inhibits mitochondrial p53 accumulation whereas inhibition of AKT function by PTEN, dominant negative AKT or inhibitors of PI3K (LY294002 and Wortmannin) and AKT promotes curcumin-induced mitochondrial import of p53. This suggests that AKT may regulate Smac release and apoptosis by attenuating the mitochondrial actions of $\mathrm{p} 53$. Furthermore, whereas the mitochondrial accumulation of p53 in response to various cellular stimuli and the proapoptotic role of mitochondrial p53 have been shown $(42,72,73)$, the present report represents, to our knowledge, the first evidence by which curcumin regulates apoptosis. Because mitochondrial p53 accumulation is correlated with p53-induced apoptosis and not cell cycle arrest (42), this strongly suggests that prevention of mitochondrial accumulation of $\mathrm{p} 53$ by AKT may be a critical intermediary step in the process of curcumininduced apoptosis.

The tumor suppressor p53 protein plays an important role in DNA repair, cell cycle arrest, and apoptosis $(46,74)$. Induction of apoptosis is considered to be central to the tumor suppressive function of $\mathrm{p} 53$. Through transcriptiondependent pathways, p53 functions as a transactivator to upregulate downstream proapoptotic genes, such as Bax, and/or functions as a repressor to down-regulate antiapoptotic genes, such as Bcl-2, promoting apoptosis. Bax promotes apoptosis by enhancing the release of mitochondrial proteins including cytochrome $\mathrm{c}$ and Smac/DIABLO. Through transcription-independent pathways, p53 has a direct apoptogenic role where it translocates to mitochondria in response to cellular stress, resulting in apoptosis via interaction with antiapoptotic $\mathrm{Bcl}-2$ and $\mathrm{Bcl}-\mathrm{X}_{\mathrm{L}}$ proteins that alter the mitochondrial membrane potential and induce cytochrome $\mathrm{c}$ and Smac release into the cytosol with resultant caspase activation (72,75).

Reactive oxygen species (ROS) induce a vide rage of responses depending on the cell type and the levels of ROS within the cell (76). High levels of ROS can lead to necrotic cell death, whereas low levels of ROS have been shown to induce apoptotic cell death $(76,77)$. ROS-mediated disruption of $\Delta \Psi_{\mathrm{m}}$ constitutes a pivotal step in the apoptotic pathway of p53. Apoptosis triggered by p53 has been reported to be dependent on an increase in ROS and the release of apoptotic factors from mitochondrial damage $(62,63)$. These studies suggest that ROS are downstream mediators in p53-dependent apoptosis in transcription-dependent or transcriptionindependent pathways. When cells are exposed to oxidative stress, such as hypoxia or genomic damage, p53 is expressed at high levels by posttranslational modifications, including phosphorylation, acetylation, and glycosylation $(64,65)$. These modifications occur rapidly and lead to the activation of p53, resulting in either G1 or G2-M cell cycle arrest or apoptosis. Therefore, ROS can function as p53 activators or p53 downstream effectors.

Epigenic modifications, mainly DNA methylation and acetylation, are recognized as additional mechanisms contributing to the malignant phenotype $(78,79)$. Histone 
acetylation is a reversible process whereby histone acetyltransferase (HAT) transfers the acetyl moiety from acetyl coenzyme A to the lysine; histone deacetylase (HDAC) removes the acetyl groups, re-establishing the positive charge in the histones. HATs and HDACs have recently been shown to regulate cell proliferation, differentiation and apoptosis in various cancers $(78,79)$. Hyperacetylation of histones correlates with gene activation, whereas deacetylation mediates eukaryotic chromatin condensation and gene expression silencing $(80,81)$. Our data have shown that curcumin induces acetylation of histone $\mathrm{H} 3$ and $\mathrm{H} 4$, suggesting that curcumin may regulate apoptosis through global regulation of genes related to cell survival and/or apoptosis. However, further studies are needed to confirm this hypothesis.

In summary, our study shows that induction of apoptosis by curcumin is ROS mediated and p53 dependent via mitochondrial pathways. Results of p53 and Bax mitochondrial translocation, cytochrome c, Omi/HtrA2 and Smac release, and caspase- 3 activation suggest that curcumin-induced apoptosis is via p53-dependent mitochondrial pathways. Furthermore, curcumin-induced acetylation and phosphorylation may stabilize p53 and thus enhance its pro-apoptotic function. Curcumin may also regulate cell survival and/or apoptosis through global modulation of gene expression via histone acetylation. In addition, our study establishes a role for AKT in modulating the direct action of p53 on the caspase-dependent mitochondrial death pathway and suggests that these important biological molecules interact at the level of the mitochondria to influence curcumin sensitivity. A thorough understanding of the mechanisms of curcumin may improve prevention outcomes for human prostate cancer.

\section{Acknowledgements}

We thank Dr William Sellers (Dana-Farber Cancer Institute, Boston, MA) for providing the pSG5-HA-PTEN-wt, pSG5HA-PTEN-G129E, and pSG5-HA-PTEN-G129R expression vectors. The project was funded by the Department of Defense grant no. W81XWH-04-1-0821.

\section{References}

1. Klein EA and Thompson IM: Update on chemoprevention of prostate cancer. Curr Opin Urol 14: 143-149, 2004.

2. Piper JT, Singhal SS, Salameh MS, Torman RT, Awasthi YC and Awasthi S: Mechanisms of anticarcinogenic properties of curcumin: the effect of curcumin on glutathione linked detoxification enzymes in rat liver. Int $\mathbf{J}$ Biochem Cell Biol 30: 445-456, 1998.

3. Susan M and Rao MN: Induction of glutathione S-transferase activity by curcumin in mice. Arzneimittelforschung 42: 962-964, 1992.

4. Sharma RA, McLelland HR, Hill KA, et al: Pharmacodynamic and pharmacokinetic study of oral Curcuma extract in patients with colorectal cancer. Clin Cancer Res 7: 1894-1900, 2001.

5. Plummer SM, Hill KA, Festing MF, Steward WP, Gescher AJ and Sharma RA: Clinical development of leukocyte cyclooxygenase 2 activity as a systemic biomarker for cancer chemopreventive agents. Cancer Epidemiol Biomarkers Prev 10: 1295-1299, 2001

6. Luo J, Manning BD and Cantley LC: Targeting the PI3K-Akt pathway in human cancer: rationale and promise. Cancer Cell 4: 257-262, 2003.

7. Cantley LC: The phosphoinositide 3-kinase pathway. Science 296: 1655-1657, 2002.
8. Lawlor MA and Alessi DR: PKB/Akt: a key mediator of cell proliferation, survival and insulin responses? J Cell Sci 114: 2903-2910, 2001

9. Datta SR, Brunet A and Greenberg ME. Cellular survival: a play in three Akts. Genes Dev 13: 2905-2927, 1999.

10. Kandasamy K and Srivastava RK: Role of the phos-phatidylinositol 3'-kinase/PTEN/Akt kinase pathway in tumor necrosis factor-related apoptosis-inducing ligand-induced apoptosis in non-small cell lung cancer cells. Cancer Res 62: 4929-4937, 2002.

11. Downward J: PI 3-kinase, Akt and cell survival. Semin Cell Dev Biol 15: 177-182, 2004.

12. Chen X, Thakkar H, Tyan F, et al: Constitutively active Akt is an important regulator of TRAIL sensitivity in prostate cancer. Oncogene 20: 6073-6083, 2001.

13. Khwaja A: Akt is more than just a Bad kinase. Nature 401: 33-34, 1999.

14. Lei H, Furlong PJ, Ra JH, et al: AKT activation and response to interferon-beta in human cancer cells. Cancer Biol Ther 4: 709-715, 2005.

15. Michl P and Downward J: Mechanisms of disease: PI3K/ AKT signaling in gastrointestinal cancers. Z Gastroenterol 43: 1133-1139, 2005.

16. Yuan XJ and Whang YE: PTEN sensitizes prostate cancer cells to death receptor-mediated and drug-induced apoptosis through a FADD-dependent pathway. Oncogene 21: 319-327, 2002.

17. Beresford SA, Davies MA, Gallick GE and Donato NJ: Differential effects of phosphatidylinositol-3/Akt-kinase inhibition on apoptotic sensitization to cytokines in LNCaP and PCc-3 prostate cancer cells. J Interferon Cytokine Res 21: 313-322, 2001.

18. Datta SR, Dudek H, Tao X, et al: Akt phosphorylation of BAD couples survival signals to the cell-intrinsic death machinery. Cell 91: 231-241, 1997

19. Lentzsch S, Chatterjee M, Gries M, et al: PI3-K/AKT/FKHR and MAPK signaling cascades are redundantly stimulated by a variety of cytokines and contribute independently to proliferation and survival of multiple myeloma cells. Leukemia 18: 1883-1890, 2004.

20. Schmidt M, Fernandez de Mattos S, van der Horst A, et al: Cell cycle inhibition by FoxO forkhead transcription factors involves downregulation of cyclin D. Mol Cell Biol 22: 7842-7852, 2002.

21. Myers MP, Pass I, Batty IH, et al: The lipid phosphatase activity of PTEN is critical for its tumor supressor function. Proc Natl Acad Sci USA 95: 13513-13518, 1998.

22. Maehama T and Dixon JE: PTEN: a tumour suppressor that functions as a phospholipid phosphatase. Trends Cell Biol 9: 125-128, 1999.

23. Davies MA, Lu Y, Sano T, et al: Adenoviral transgene expression of MMAC/PTEN in human glioma cells inhibits Akt activation and induces anoikis. Cancer Res 58: 5285-5290, 1998.

24. Li J, Yen C, Liaw D, et al: PTEN, a putative protein tyrosine phosphatase gene mutated in human brain, breast, and prostate cancer. Science 275: 1943-1947, 1997.

25. Wu X, Senechal K, Neshat MS, Whang YE and Sawyers CL: The PTEN/MMAC1 tumor suppressor phosphatase functions as a negative regulator of the phosphoinositide 3-kinase/Akt pathway. Proc Natl Acad Sci USA 95: 15587-15591, 1998.

26. Green DR and Amarante-Mendes GP: The point of no return: mitochondria, caspases, and the commitment to cell death. Results Probl Cell Differ 24: 45-61, 1998.

27. Du C, Fang M, Li Y, Li L and Wang X: Smac, a mitochondrial protein that promotes cytochrome c-dependent caspase activation by eliminating IAP inhibition. Cell 102: 33-42, 2000

28. Verhagen AM, Coulson EJ and Vaux DL: Inhibitor of apoptosis proteins and their relatives: IAPs and other BIRPs. Genome Biol 2: reviews, 3009, 2001.

29. Verhagen AM and Vaux DL: Cell death regulation by the mammalian IAP antagonist Diablo/Smac. Apoptosis 7: 163-166, 2002.

30. MacFarlane M, Merrison W, Bratton SB and Cohen GM: Proteasome-mediated degradation of Smac during apoptosis: XIAP promotes Smac ubiquitination in vitro. J Biol Chem 277: 36611-36616, 2002.

31. Vyas S, Juin P, Hancock D, et al: Differentiation-dependent sensitivity to apoptogenic factors in PC12 cells. J Biol Chem 279: 30983-30993, 2004.

32. Verhagen AM, Ekert PG, Pakusch M, et al: Identification of DIABLO, a mammalian protein that promotes apoptosis by binding to and antagonizing IAP proteins. Cell 102: 43-53, 2000 
33. Kandasamy K, Srinivasula SM, Korsmeyer SJ, et al: Involvement of proapoptotic molecules Bax and Bak in tumor necrosis factorrelated apoptosis-inducing ligand (TRAIL)-induced mitochondrial disruption and apoptosis: differential regulation of cytochrome c and Smac/ DIABLO release. Cancer Res 63: 1712-1721, 2003.

34. Levine AJ, Momand $\mathbf{J}$ and Finlay CA: The p53 tumour suppressor gene. Nature 351: 453-456, 1991

35. Haupt S, Berger M, Goldberg Z and Haupt Y: Apoptosis - the p53 network. J Cell Sci 116: 4077-4085, 2003.

36. Honda R, Tanaka H and Yasuda H: Oncoprotein MDM2 is a ubiquitin ligase E3 for tumor suppressor p53. FEBS Lett 420: 25-27, 1997.

37. Ashcroft M, Kubbutat MH and Vousden KH: Regulation of p53 function and stability by phosphorylation. Mol Cell Biol 19: 1751-1758, 1999

38. Grossman SR, Deato ME, Brignone C, et al: Polyubiquitination of p53 by a ubiquitin ligase activity of p300. Science 300: 342-344, 2003

39. Moll UM and Petrenko O: The MDM2-p53 interaction. Mol Cancer Res 1: 1001-1008, 2003.

40. Johnstone RW, Ruefli AA and Lowe SW: Apoptosis: a link between cancer genetics and chemotherapy. Cell 108: 153-164, 2002.

41. Chipuk JE, Kuwana T, Bouchier-Hayes L, et al: Direct activation of Bax by 53 mediates mitochondrial membrane permeabilization and apoptosis. Science 303: 1010-1014, 2004.

42. Mihara M, Erster S, Zaika A, et al: p53 has a direct apoptogenic role at the mitochondria. Mol Cell 11: 577-590, 2003.

43. Chipuk JE, Bouchier-Hayes L, Kuwana T, Newmeyer DD and Green DR: PUMA couples the nuclear and cytoplasmic proapoptotic function of p53. Science 309: 1732-1735, 2005.

44. Slee EA, O'Connor DJ and $\mathrm{Lu} \mathrm{X}$ : To die or not to die: how does p53 decide? Oncogene 23: 2809-2818, 2004.

45. Yakovlev AG, Di Giovanni S, Wang G, Liu W, Stoica B and Faden AI: BOK and NOXA are essential mediators of p53dependent apoptosis. J Biol Chem 279: 28367-28374, 2004.

46. Vousden KH and Lu X: Live or let die: the cell's response to p53. Nat Rev Cancer 2: 594-604, 2002.

47. Shankar S, Singh TR and Srivastava RK: Ionizing radiation enhances the therapeutic potential of TRAIL in prostate cancer in vitro and in vivo: intracellular mechanisms. Prostate 61: 35-49, 2004.

48. Shankar S, Chen X and Srivastava RK: Effects of sequential treatments with chemotherapeutic drugs followed by TRAIL on prostate cancer in vitro and in vivo. Prostate 62: 165-186, 2005.

49. Reers M, Smith TW and Chen LB: J-aggregate formation of a carbocyanine as a quantitative fluorescent indicator of membrane potential. Biochemistry 30: 4480-4486, 1991.

50. Shankar S, Singh TR, Chen X, Thakkar H, Firnin J and Srivastava RK: The sequential treatment with ionizing radiation followed by TRAIL/Apo-2L reduces tumor growth and induces apoptosis of breast tumor xenografts in nude mice. Int $\mathrm{J}$ Oncol 24: 1133-1140, 2004.

51. Shankar S, Singh TR, Fandy TE, Luetrakul T, Ross DD and Srivastava RK: Interactive effects of histone deacetylase inhibitors and TRAIL on apoptosis in human leukemia cells: Involvement of both death receptor and mitochondrial pathways. Int J Mol Med 16: 1125-1138, 2005.

52. Shankar S and Srivastava RK: Enhancement of therapeutic potential of TRAIL by cancer chemotherapy and irradiation: mechanisms and clinical implications. Drug Resist Updat 7: 139-156, 2004.

53. Cory S and Adams JM: The Bcl2 family: regulators of the cellular life-or-death switch. Nat Rev Cancer 2: 647-656, 2002.

54. Manion MK and Hockenbery DM: Targeting BCL-2-related proteins in cancer therapy. Cancer Biol Ther 2: S105-S114, 2003.

55. Singh TR, Shankar S and Srivastava RK: HDAC inhibitors enhance the apoptosis-inducing potential of TRAIL in breast carcinoma. Oncogene 24: 4609-4623, 2005.

56. Arnoult D, Parone P, Martinou JC, Antonsson B, Estaquier J and Ameisen JC: Mitochondrial release of apoptosis-inducing factor occurs downstream of cytochrome $c$ release in response to several proapoptotic stimuli. J Cell Biol 159: 923-929, 2002.
57. Uren RT, Dewson G, Bonzon C, Lithgow T, Newmeyer DD and Kluck RM: Mitochondrial release of pro-apoptotic proteins: electrostatic interactions can hold cytochrome c but not Smac/ DIABLO to mitochondrial membranes. J Biol Chem 280: 2266-2274, 2005.

58. Bouchier-Hayes L, Lartigue L and Newmeyer DD: Mitochondria: pharmacological manipulation of cell death. J Clin Invest 115: 2640-2647, 2005

59. Green DR and Kroemer G: The pathophysiology of mitochondrial cell death. Science 305: 626-629, 2004.

60. Degenhardt K, Sundararajan R, Lindsten T, Thompson C and White E: Bax and Bak independently promote cytochrome C release from mitochondria. J Biol Chem 277: 14127-14134, 2002.

61. Mikhailov V, Mikhailova M, Degenhardt K, Venkatachalam MA, White E and Saikumar P: Association of Bax and Bak homooligomers in mitochondria. Bax requirement for Bak reorganization and cytochrome c release. J Biol Chem 278: 5367-5376, 2003.

62. Polyak K, Xia Y, Zweier JL, Kinzler KW and Vogelstein B: A model for p53-induced apoptosis. Nature 389: 300-305, 1997.

63. Macip S, Igarashi M, Berggren P, Yu J, Lee SW and Aaronson SA Influence of induced reactive oxygen species in p53-mediated cell fate decisions. Mol Cell Biol 23: 8576-8585, 2003.

64. Bode AM and Dong Z: Post-translational modification of $\mathrm{p} 53$ in tumorigenesis. Nat Rev Cancer 4: 793-805, 2004

65. Chandel NS, Vander Heiden MG, Thompson CB and Schumacker PT: Redox regulation of p53 during hypoxia. Oncogene 19: 3840-3848, 2000.

66. Leone G, Voso MT, Teofili L and Lubbert M: Inhibitors of DNA methylation in the treatment of hematological malignancies and MDS. Clin Immunol 109: 89-102, 2003.

67. Kroemer G: Mitochondrial control of apoptosis: an overview. Biochem Soc Symp 66: 1-15, 1999.

68. Li PF, Dietz R and von Harsdorf R: p53 regulates mitochondrial membrane potential through reactive oxygen species and induces cytochrome c-independent apoptosis blocked by Bcl-2. EMBO J 18: 6027-6036, 1999.

69. Liu J, Yin S, Reddy N, Spencer C and Sheng S: Bax mediates the apoptosis-sensitizing effect of maspin. Cancer Res 64: 1703-1711, 2004.

70. Maianski NA, Geissler J, Srinivasula SM, Alnemri ES, Roos D and Kuijpers TW: Functional characterization of mitochondria in neutrophils: a role restricted to apoptosis. Cell Death Differ 11: 143-153, 2004.

71. Majewski N, Nogueira V, Robey RB and Hay N: Akt inhibits apoptosis downstream of BID cleavage via a glucose-dependent mechanism involving mitochondrial hexokinases. Mol Cell Biol 24: 730-740, 2004.

72. Marchenko ND, Zaika A and Moll UM: Death signal-induced localization of $\mathrm{p} 53$ protein to mitochondria. A potential role in apoptotic signaling. J Biol Chem 275: 16202-16212, 2000.

73. Erster S, Mihara M, Kim RH, Petrenko O and Moll UM: In vivo mitochondrial p53 translocation triggers a rapid first wave of cell death in response to DNA damage that can precede p53 target gene activation. Mol Cell Biol 24: 6728-6741, 2004.

74. Hofseth LJ, Saito S, Hussain SP, et al: Nitric oxide-induced cellular stress and p53 activation in chronic inflammation. Proc Natl Acad Sci USA 100: 143-148, 2003

75. Yang X, Fraser M, Moll UM, Basak A and Tsang BK: Aktmediated cisplatin resistance in ovarian cancer: modulation of p53 action on caspase-dependent mitochondrial death pathway. Cancer Res 66: 3126-3136, 2006.

76. Kannan K and Jain SK: Oxidative stress and apoptosis. Pathophysiology 7: 153-163, 2000.

77. Kroemer G, Zamzami N and Susin SA: Mitochondrial control of apoptosis. Immunol Today 18: 44-51, 1997.

78. Plass C: Cancer epigenomics. Hum Mol Genet 11: 2479-2488, 2002.

79. Jones PA: DNA methylation and cancer. Oncogene 21: 5358-5360, 2002.

80. Strahl BD and Allis CD: The language of covalent histone modi-fications. Nature 403: 41-45, 2000.

81. Johnstone RW: Histone-deacetylase inhibitors: novel drugs for the treatment of cancer. Nat Rev Drug Discov 1: 287-299, 2002 . 